\title{
SHEAR EVALUATION OF TAPERED BRIDGE GIRDER PANELS WITH STEEL CORRUGATED WEBS NEAR THE SUPPORTS OF CONTINUOUS BRIDGES
}

\author{
E. ZEVALLOS", M. F. HASSANEIN ${ }^{\#, I}$, E. REAL ${ }^{*}$ E. MIRAMBELL* \\ * Department of Construction Engineering, Universitat Politècnica de Catalunya, UPC, \\ C/Jordi Girona, 1-3.08034 Barcelona, Spain \\ \# Department of Structural Engineering, Faculty of Engineering, Tanta University, \\ Tanta, Egypt
}

\begin{abstract}
Because of public construction budgets were cut over the last few years, new bridge girders with corrugated webs to reduce the construction costs have become more widely studied and used. In spite that tapered bridge girders with corrugated webs (BGCWs) are used in modern bridges, their shear strength and behaviour rarely exists in literature. Based on available literature, the web of the linearly tapered BGCWs may be divided into three typologies with different structural response to shear force. This paper presents a study into the shear strength and behaviour of the different web panels of the tapered BGCWs near the end and intermediate supports of continuous bridges using the dimensions of constructed bridges. Accordingly, parametric studies are conducted with variations in the aspect ratio of the web panel, different inclination angles of the tapered web panel and the flange slenderness ratio. After that, the paper checks the available design model under these additional parametric study models. The paper is extended to check corrugation dimensions for the use in conventional structures. It is noticed that as the corrugation angle $(\alpha)$ between longitudinal and inclined sub-panels decreases, the ultimate shear of the girders decreases because the rigidity of the web decreases. The available design model is compared to the FE results and it is found to yield suitable results for girders used in bridges as well as conventional structures.
\end{abstract}

\footnotetext{
${ }^{1}$ Corresponding author (Mobile: +201228898494; Fax: +20403315860; E-mail: mostafa.fahmi@yahoo.com, mostafa.fahmi@f-eng.tanta.edu.eg).
} 
Overall, new conclusions on the shear strength and behaviour of tapered BGCWs are presented.

\section{KEYWORDS}

Tapered corrugated steel webs, Shear strength, Interactive buckling, Initial imperfection, Inclination angle.

\section{INTRODUCTION}

In case of I-section plate girders (IPGs) with slender webs, the web panel buckles at a relatively low value of the applied load. Hence, to overcome the strength reduction associated with utilizing plate girders with slender webs in bridge construction, these flat webs are often reinforced with transversal stiffeners along their spans to increase their buckling strength. Recently, girders with steel corrugated webs (BGCWs) have been used as structural members in long span beams and bridges. Several examples representing the BGCWs may be found in literature with Maupré Bridge shown in Fig. 1(a) being one of them. This bridge was built by using trapezoidally corrugated steel web plate, which is the most commonly used corrugation type that compose of a series of longitudinal and inclined sub-panels. Because of their significant out-of-plane stiffness, corrugated web plates have much higher buckling strengths compared with flat web plates. Hence, the necessity of using stiffeners is eliminated and the required web thickness is reduced [1-5]. Additionally, the flexural strength of such girders is entirely provided by their flanges while the shear strength is provided by their webs due to the negligible axial stiffness of the corrugated webs in the longitudinal direction of the girders which is commonly known as the accordion effect [6-8]. It was proved [6-8] that the axial stiffness of the corrugated steel plates is negligible by nature of their unique geometric characteristics, while they own very high vertical stiffness to fully transmit vertical shear. 
Consequently, there is no interaction between shear and flexural behaviours of the BGCWs. Hence, BGCWs make the best use of the effective material properties of both flanges and webs. It was additionally found that the weight of the BGCWs can be $10 \%$ less than the weight of the original IPGs with the same static capacity [9-10]. However, it is worth pointing out that the corrugated webs under shear loading may buckle locally, globally or interactively. The first mode is controlled by deformations within a single sub-panel of the web. The second mode involves multiple sub-panels and the buckled shape extends diagonally over the depth of the web. However, experimental and finite element observed buckling often appears to have characteristics of both local and global buckling modes. This was classified as an interactive buckling mode and Lindner and Aschinger [11], historically, were the first to provide its elastic buckling formula. Recently, tapered girders have been used in bridges based on their structural efficiency, providing at the same time aesthetical appearance. Fig. 1(b) shows an example of bridges that utilise tapered BGCWs: the Dole Bridge. The linearly tapered BGCW selected as the subject of this study is shown in Fig. 2. As can be seen, it is a continuous bridge composed of two spans. In spite that the advantages of corrugated webs were found to be greater in box girders, as those used in Maupré and Dole Bridges, than in plate girders [12], their main structural properties can be deduced from work on plate girders [1-10]. 


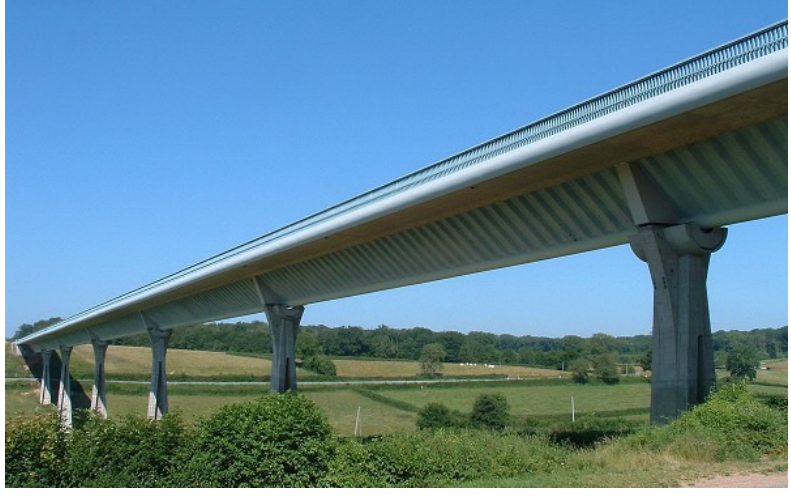

(a) Prismatic bridge girders

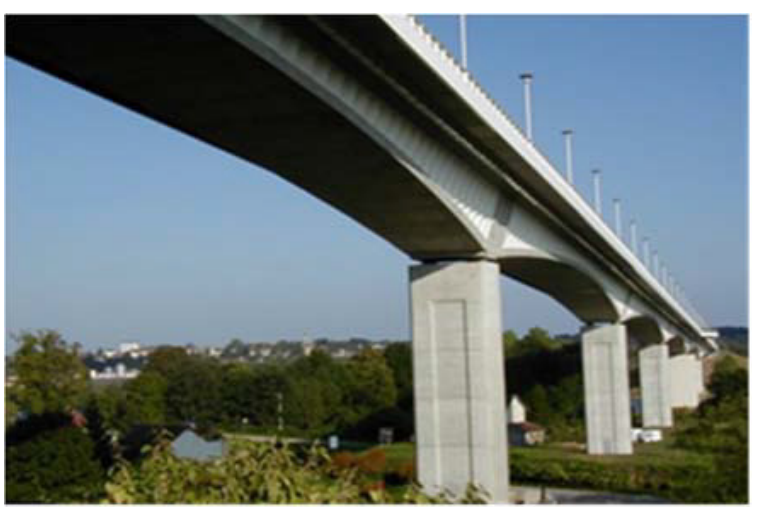

(b) Tapered bridge girders

Fig. 1: Bridge girders with corrugated webs: (a) Maupré Bridge and (b) Dole Bridge

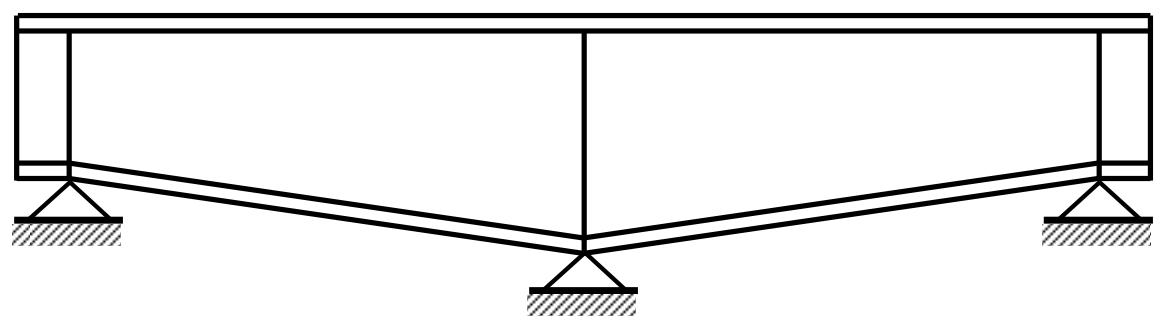

Fig. 2: Considered linearly tapered continuous two-span BGCW

Based on previous researches [13-14], the web of the tapered girder may be classified into three typologies. This classification is based on (1) the inclination of the flange and whether the flange is under tension or compression and (2) the direction of the developed tension field, which may appear on the short or on the long web diagonal [13]. However, the check of shear of the girder (Fig. 2) should be preceded by an elastic analysis for bending and shear. The purpose of such analysis is to determine the bending moment and shear force distributions throughout the girder, so that (1) the girder can be divided into different typologies and (2) the maximum shear forces can be found and compared with the shear capacities of each typology. Fig. 3 provides the bending moment and shear force diagrams, where the points of zero moment and zero shear divide the web into three typologies; I, II and III IV, with the boundary cross-sections of each typology (defined by digits in Fig. 3c) should 
be checked in design. It should be noted that Refs. [13-14] provide the general behaviour of the different typologies of the linearly tapered girders with flat and corrugated webs, respectively. Owing to the lack of research papers related to tapered BGCWs, this paper, which is a part from the Master thesis of the first author [15], provides the behaviour of Cases I and II web panels existing in linearly tapered BGCWs which lay near the supports of continuous bridges, with the contribution of this paper can be summarised as:

1. More realistic corrugation dimensions using those of Maupré and Dole bridges were used. This increases the data points available in literature which has concentrated on Shinkai and Matsnoki bridges [14].

2. Initial imperfections were linked in this paper to the height of the girders with values of $h_{w 1} / 200$ following the Eurocode, instead of the value used by Hassanein and Kharoob [14] which was taken equal to the web thickness.

3. The failure mode of the BGCWs which differs from the case of tapered bridge girders with flat flanges was monitored and deeply analysed.

4. BGCWs with different web plate aspect ratios $\left(a / h_{w 1}\right)$ were considered to get the relationship between them and their ultimate shear capacities.

5. The relationship between the increase in strength and the increase in weight associated with the increase of the web thickness was investigated. A new corrugation configuration using two web plates are then suggested.

6. The effect of the inclination angle $(\gamma)$ on the load-deformation response of the BGCWs was checked with general results provided.

7. The paper is extended to check the effect of the corrugation dimensions for the use in conventional structures, as an attempt to provide unified design models for girders 
used in bridges as well as conventional structures. Also, to provide the lower bound of the corrugation angle between the sub-panels of the BGCWs which provides adequate support to one another along the fold lines.

It is worth pointing out that Case III typology was neglected in this paper because its critical cross-section (i.e. the shorter depth within Case III typology termed as section 4 in Fig. 3c) is at the point of zero shear.

a)

b)

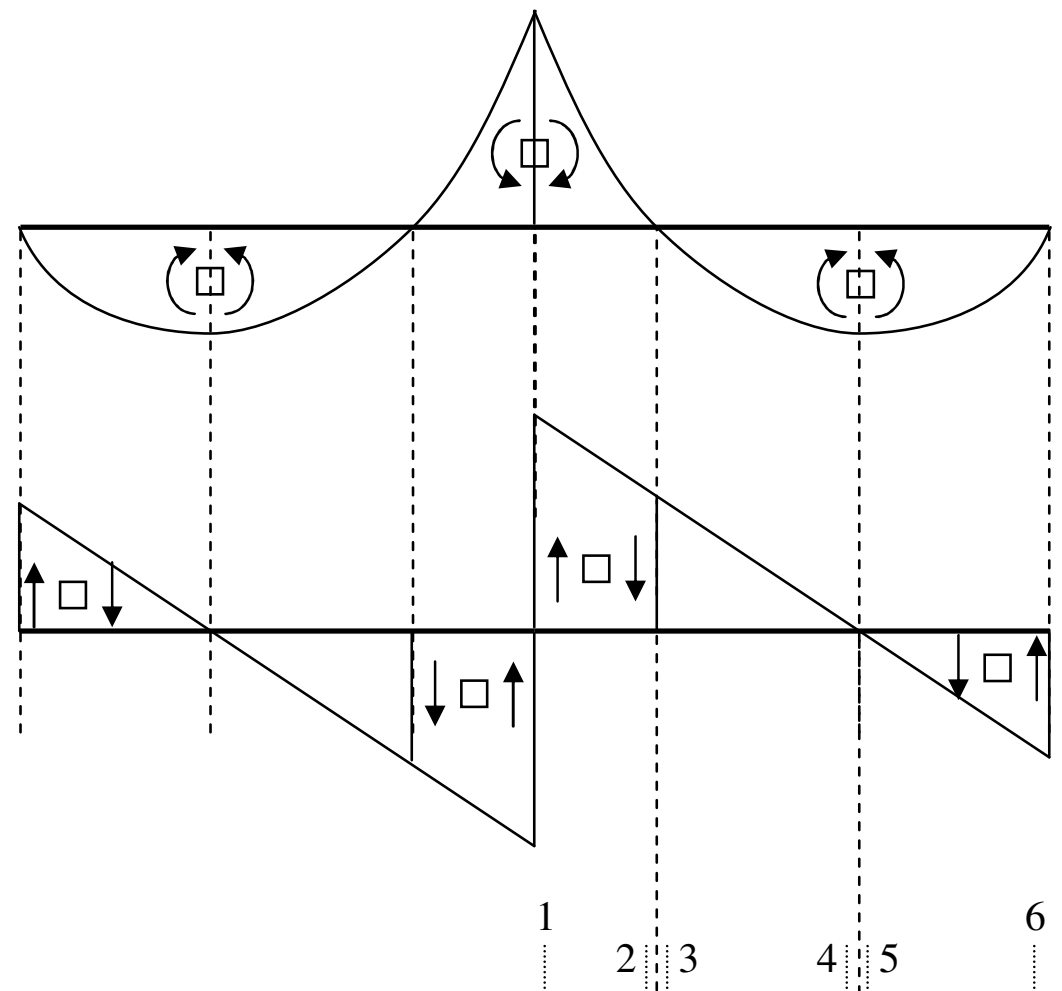

c)

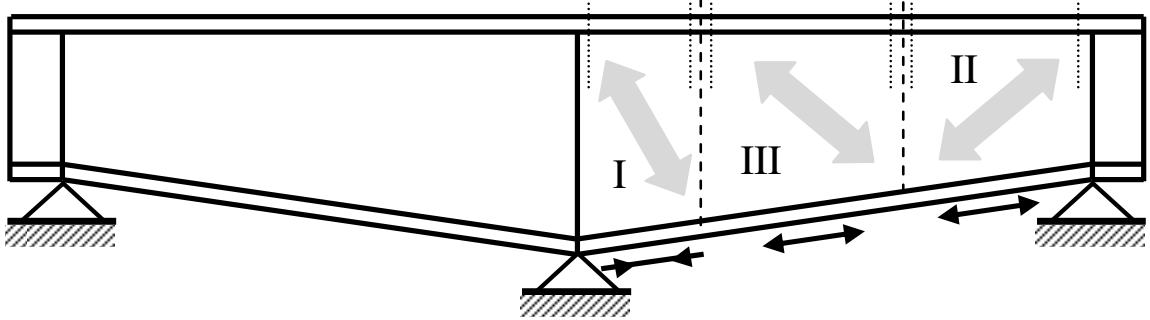

Direction of Tension Field

$\longleftrightarrow$ Tension on tapered flange

$\rightarrow$ Compression on tapered flange

Fig. 3: Classification of the web into different typologies; (a) bending moment diagram, (b) shear force diagram and (c) web typology 


\section{FINITE ELEMENT MODEL AND VALIDATION}

\subsection{Numerical model}

ABAQUS [16] FE package was used in this paper to generate finite element (FE) models representing different types of web panels. This section provides the details and the validation of the current FE models. To investigate each typology extensively without interactions with each other, several full-scale simple-span BGCWs representing Cases I and II were simulated as can be seen in Fig. 4. According to the classification shown in Fig. 3c, Case I BGCWs represent girders where the inclined flange is under compression and the developed tension field appears on the short web diagonal, while Case II BGCWs are those with inclined flanges loaded under tension and the long web diagonals coincide with the developed tension fields.

A two-step approach was used in the present simulation of tapered BGCWs to include initial geometric imperfections. In the first step, an elastic buckling analysis was performed on a perfect BGCW to obtain its buckling mode. In the second step, initial geometric imperfections based on the first buckling mode were included in the nonlinear analysis of the BGCW under mid-span concentrated load using the modified RIKS method [16]. Hence, within each shear span $(a)$ of the current simply supported girders, the shear force is constant. Simply supported boundary conditions were applied to end supports defined at the lower flange at $x=0.0$ and $x=2 a$. At each support, the twist rotation about $x$-axis of all nodes was restrained $\left(\phi_{x}=0.0\right)$. The lateral displacement in z-axis was restrained $\left(u_{z}=0.0\right)$. The vertical displacement of the web was restrained $\left(u_{y}=0.0\right)$, while the longitudinal displacement in $\mathrm{x}$-axis of a centre point at the lower flange was restrained $\left(u_{z}=0.0\right)$. The vertical concentrated load was applied in the mid-span. To prevent the flexural-torsional 
buckling, lateral displacements were restrained at the loaded mid-span points. The non-linear geometry parameter (NLGEOM) was included to deal with the large displacement analysis. S8R5 reduced integration thin shell elements were employed to discretise the BGCWs in the current nonlinear analysis. Simpson rule with five integration points was used through the included element thickness. For the current tapered BGCWs involving buckling, a convergence test was carried out in order to assess the requirement of the mesh refinement of the FE discretisation. Eight elements across each fold of the corrugation (Fig. 5) were employed in the current analysis because it was found to provide accurate results with good solution timing. As recommended in Annex C.6 of EC3-1-5 [17], which gives guidance on the use of FE-methods of plated structures, a bilinear elastic-plastic stress-strain curve with linear strain hardening was adopted to simulate the steel material, as can be seen in Fig. 6 . Initial geometric imperfections, based on the first positive shear buckling mode, were included in the nonlinear analysis of the current BGCWs. The vertical displacement history was applied to the FE models along their mid-span web points at the intersection with lower flanges.

(a) Case I

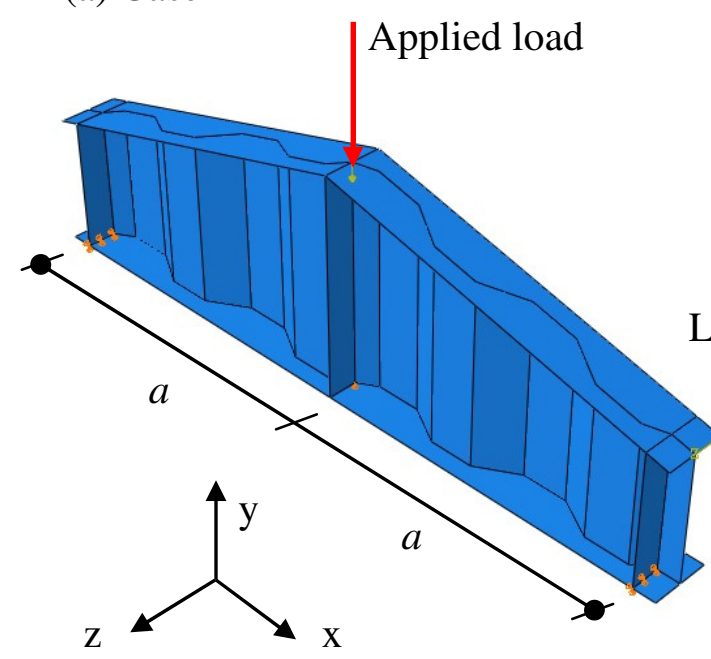

(b) Case II

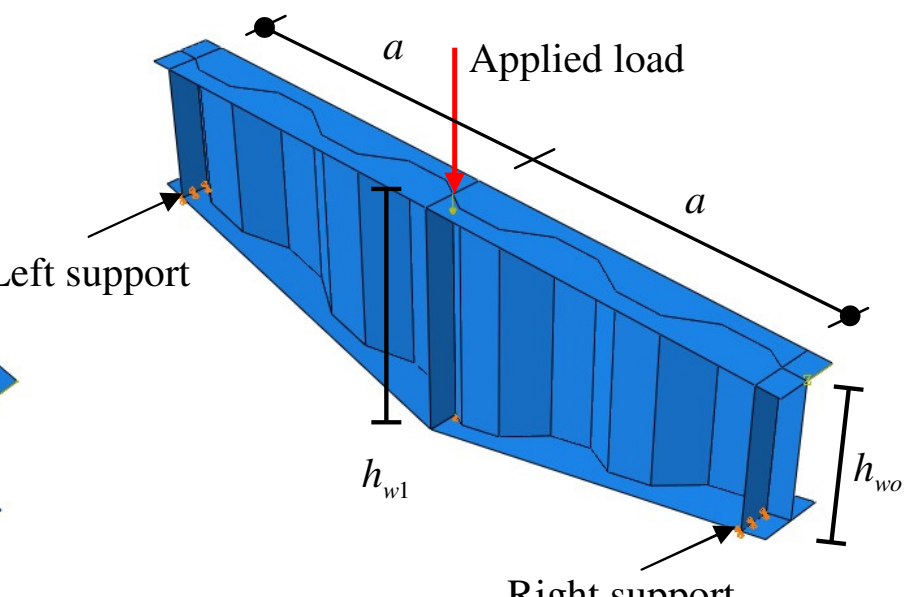

Right support

Fig. 4: FE models of tapered BGCWs; (a) Case I and (b) Case II 


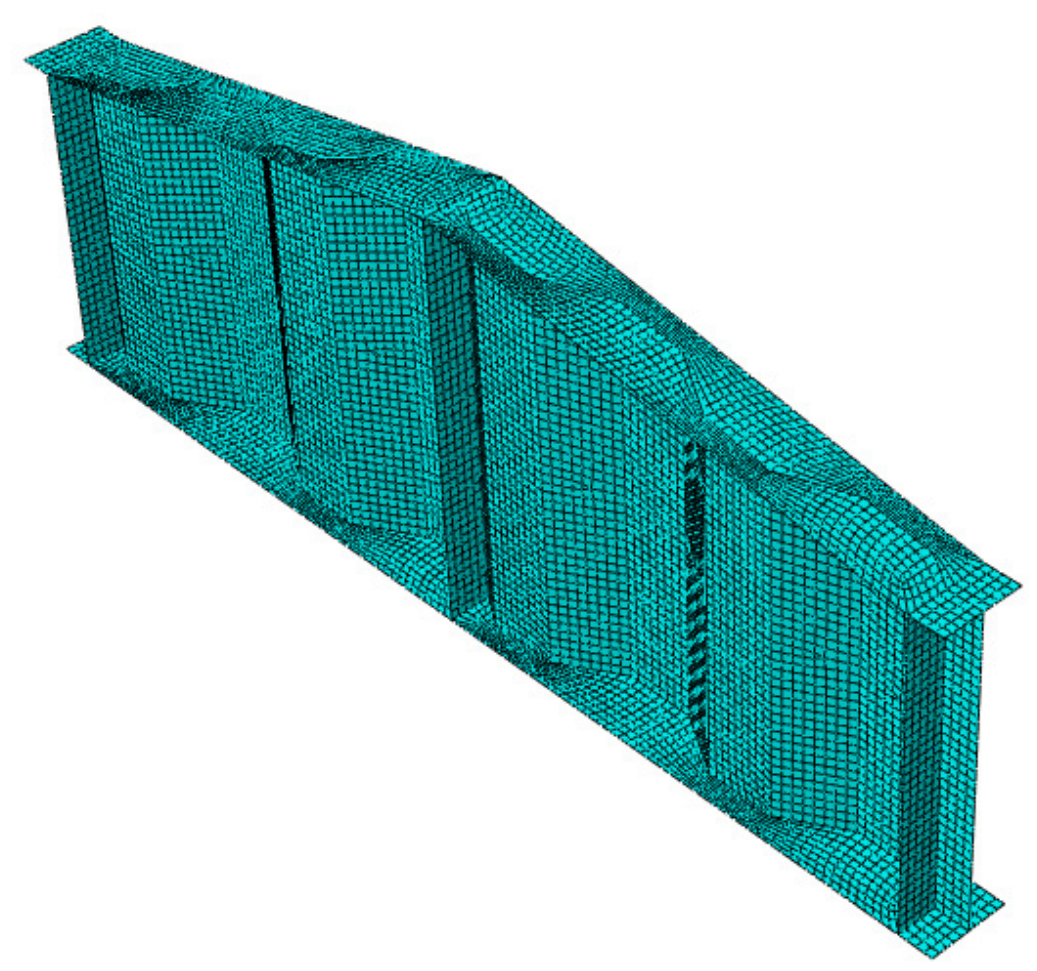

Fig. 5: FE mesh of a typical bridge girder

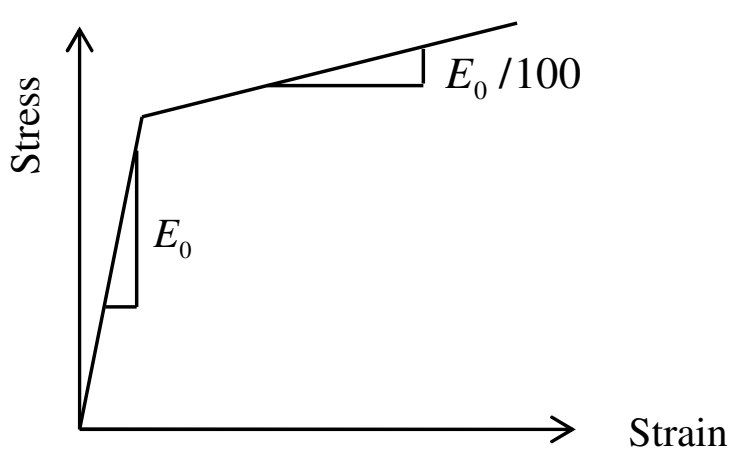

Fig. 6: Adopted bilinear stress-strain curve for the steel material

\subsection{Validation}

In spite the use of tapered BGCWs in practice (Fig. 1(b)), there are no experimental results in literature investigating their behaviour. Hence, the current validation for the models is made by using the results available for prismatic BGCWs; i.e. girders with constant depths. Even though the literature contains several experimental works on the shear behaviour of prismatic BGCWs as those found in Refs. $[2,7-8,18]$, most of them did not report the measured values for initial imperfections [2,7] nor the geometrical details of the flanges [8]. Specimen M12 of 
Moon et al. [2] and G7A tested by Driver et al. [7] were the only test specimens found by the authors with all details given, with all details for G7A test is given in Ref. [19]. Hence, they were used in the current validation. Table 1 provides the full details of these specimens using the geometric notations as provided in Fig. 7.

The comparisons presented in Figs. 8 and 9 show that the current modelling mostly reflects the real behaviour of the prismatic BGCWs M12 and G7A. The FE to experimental ultimate stress $\left(\tau_{F E} / \tau_{e}\right)$ ratios for M12 and G7A are 1.03 and 0.99 , respectively. It can be seen from Fig. 8 that the FE and the experimental results follow the same trend but have somewhat lower experimental strengths compared to that of the FE results. This difference for the case of M12 is attributed to the fact that the imperfection shape used in the finite element study, from the first eigenvalue analysis as commonly used in literature, is different from that of the real girder which was found to concentrate near the compression flange of the girder [2]. Also, the position of the maximum initial imperfection of girder G7A found in the fold just beside the applied load [7] differs from that of the FE. In the FE simulation, the first positive eigenmode was scaled and added to the model in the nonlinear solution. This involves buckles in the folds that have out-of-plane deformations increasing in the centreline of the web panel neither near the edges of the panel nor the applied load as found experimentally. Hence, this decreases the initial stiffness of the experimental girder by increasing the vertical deflection under the applied load from the beginning of the loading process. To raise the confidence of the current FE models, the verification extended to the tapered girders with conventional flat web [13]. Here Fig. 10 shows the validation of Specimen D, at which it can be seen that current modelling simulates well the behaviour of the tapered girders. This, however, shows that the deviation between the initial stiffnesses in case of the tapered BGCWs is related to the difference in the initial imperfection patterns as discussed above. By 
just modifying the depth of the web within the girder, the same model is considered to represent the actual behaviour of the tapered BGCWs.

Table 1: Profiles of available tests for BGCWs [2,7]

\begin{tabular}{|c|c|c|c|c|c|}
\hline Girder & $b[\mathrm{~mm}]$ & $d[\mathrm{~mm}]$ & $t_{w}[\mathrm{~mm}]$ & $h_{w}[\mathrm{~mm}]$ & $\left.\alpha{ }^{\circ}\right]$ \\
\hline M12 [2] & 250 & 220 & 4.0 & 2000 & 17.18 \\
\hline G7A [7] & 300 & 200 & 6.3 & 1500 & 36.9 \\
\hline
\end{tabular}

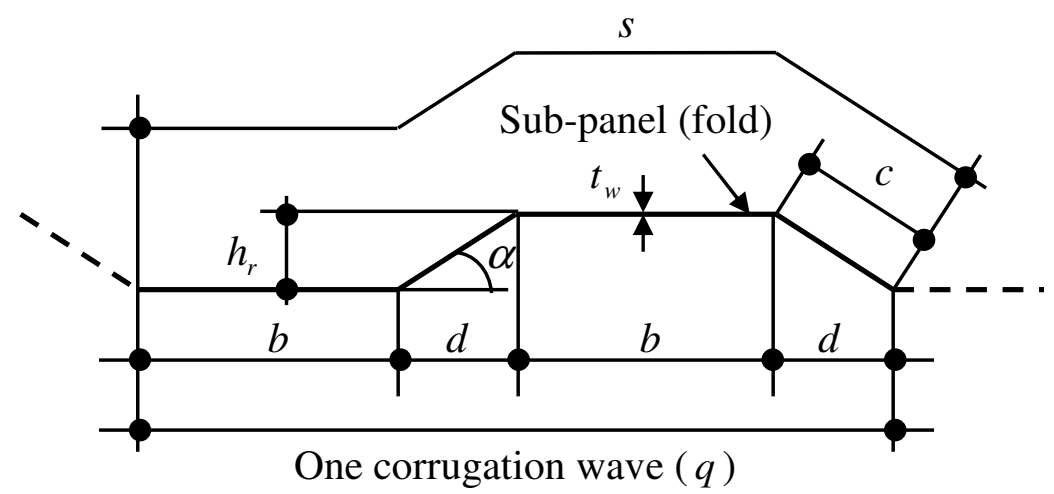

Fig. 7: Corrugation configuration and geometric notation

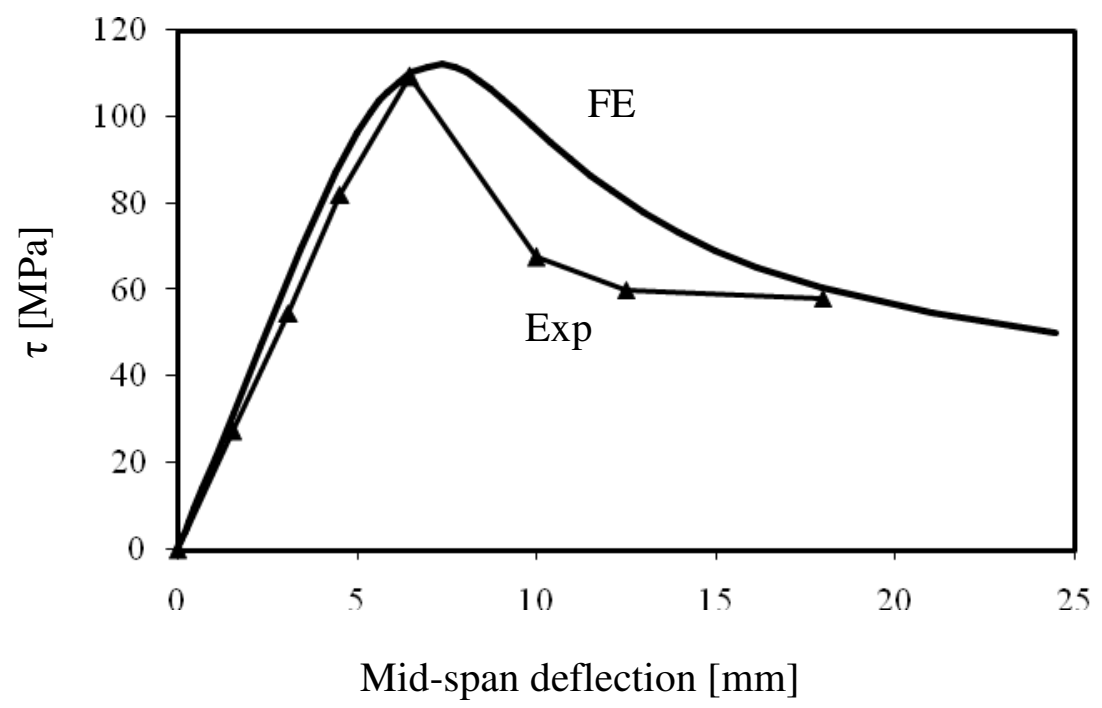

Fig. 8: Shear stress versus mid-span deflection for Specimen M12 [2] 


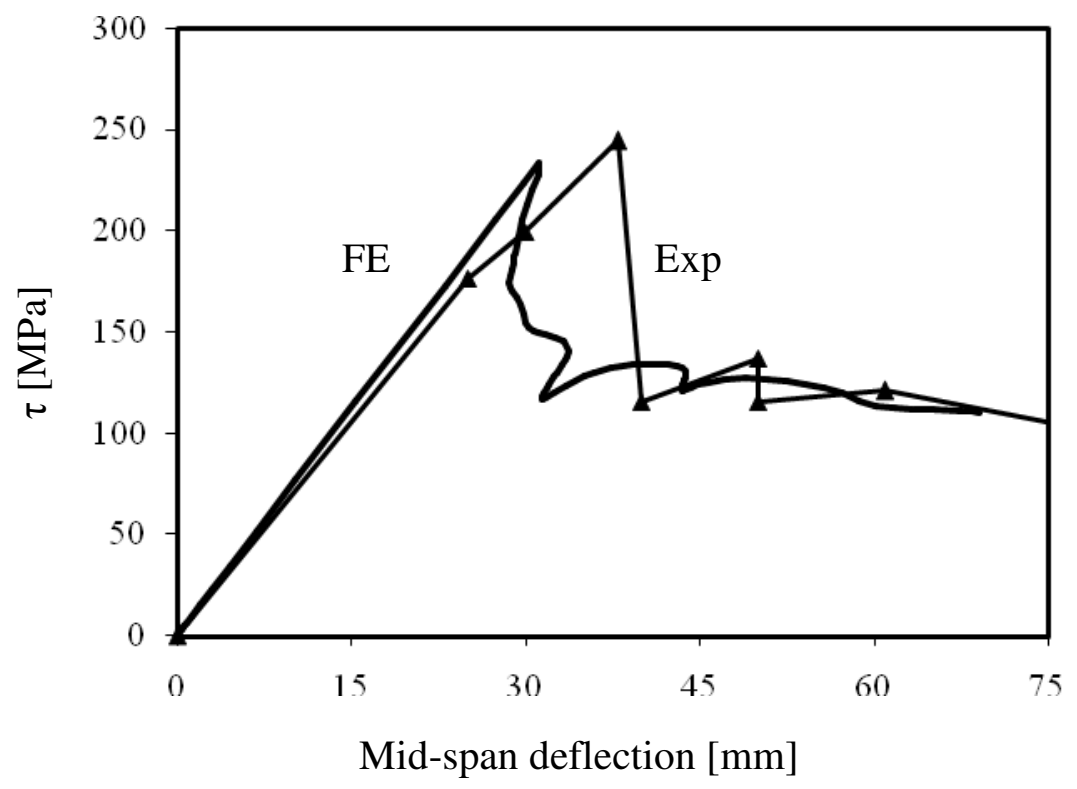

Fig. 9: Shear stress versus mid-span deflection for Specimen G7A [7]

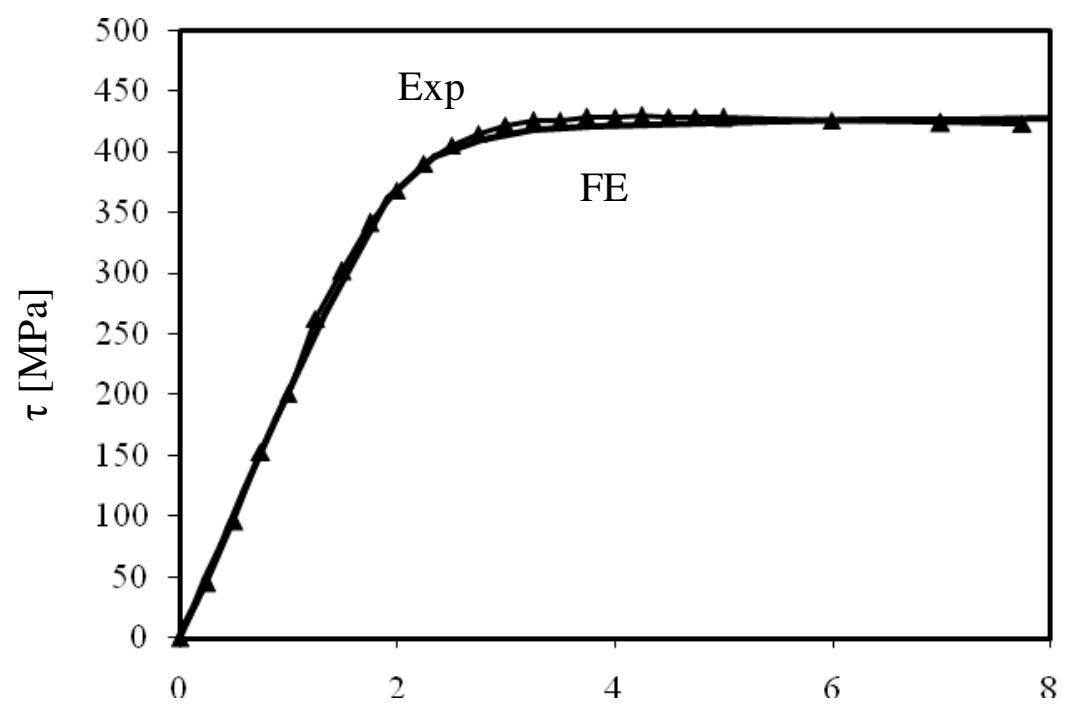

Fig. 10: Shear stress versus mid-span deflection for Specimen D [13]

\section{PARAMETRIC STUdY}

Full-scale tapered BGCWs loaded under mid-span concentrated loads of Cases I and II (Fig.

4) were generated in this paper using the corrugation dimensions of Maupré and Dole bridges. Actually, the safety of the constructed bridges was confirmed by three-dimensional finite element analysis and loading experiments using half-scale model specimens [20]. Therefore, this parametric study was generated to substitute the lack of available design shear 
strengths of tapered BGCWs. Table 2 and Table 3 provide the details and FE results of the tapered BGCWs with Case I and II of Maupré Bridge, respectively; for other results refer to Ref. [15]. These corrugation dimensions (i.e. Maupré and Dole bridges) were chosen to increase the data points available in literature which has concentrated on Shinkai and Matsnoki bridges [14] and to add new results to literature. The loaded point was restrained laterally in order that the shear controls the failure modes of the tapered BGCWs. The web thickness was varied between 4 and $14 \mathrm{~mm}$. Initial geometric imperfections, based on the first positive shear buckling mode, were included in the nonlinear analysis of the BGCW with values of $h_{w 1} / 200$ [17]. Simply supported boundary conditions were applied to end sections. The steel material has been modelled as a von Mises material with isotropic hardening. The steel used was S355 according to EN 1993-1-1 [21], which has a yield $\left(f_{y}\right)$ and an ultimate strength $\left(f_{u}\right)$ of $355 \mathrm{MPa}$ and $510 \mathrm{MPa}$, respectively.

Currently, three-dimensional FE models, using ABAQUS [16] FE package, were performed on one hundred sixty six tapered BGCWs which cover the following parameters:

1. aspect ratio of the web panels $\left(a / h_{w 1}\right) ;(1.28,1.92$ and 2.56$)$,

2. angle of the inclined flanges $(\gamma) ;\left(10,15,20,25^{\circ}\right)$, and

3. web thickness $\left(t_{w}\right) ;(4,6,8,10,12$, and $14 \mathrm{~mm})$.

The web depth $\left(h_{w 1}\right)$ was taken as $2500 \mathrm{~mm}$ while the depth $h_{w o}$ varied with different angle of inclination of the flanges $(\gamma)$. A thick flange with a thickness of $50 \mathrm{~mm}$ was considered in the current parametric study to provide strong constraint to the corrugated webs as found by $\mathrm{He}$ et al. [22]. According to Basler and Thurlimann [23], the flanges are assumed to have small bending stiffness and the tension field is attached to the transverse stiffeners. On the opposite, 
when the flanges are thick, they provide strong constraint to the web so that the tension field is attached to both the flanges and the stiffeners; refer for example to Cardiff method [24]. Also, thick flanges provide fixed boundary conditions at the juncture between the flanges and the webs [25]. For the case of BGCWs, it was found that increasing the thickness of the flange beyond three times that of the web, the juncture becomes fixed [4]. Additionally, the relatively high flange thickness represents cases where the corrugated webs are embedded in the concrete slab as the case of Kurobegawa bridge [20]. Throughout the entire programme, the flange width $\left(b_{f}\right)$ was fixed to $500 \mathrm{~mm}$ and the webs were stiffened transversely at the points subjected to concentrated loads; i.e. the supports and under the mid-span applied load. It should be noted that the stiffeners were realised from early days to have no effect on the shear buckling mode and shear buckling strength of the BGCWs. Hence, constructed bridges as those shown in Fig. 1 do not use stiffeners. The considered double-sided out-standing plate stiffeners extended to the edge of the flanges with a thickness of $25.4 \mathrm{~mm}$ throughout the paper. As it is well known, the type of the end post (refer to [17]) depends on the longitudinal membrane stresses in the plane of the web. Hence, when these stresses are large, the rigid end post composing, for example, of two double-sided stiffeners should be used. Currently, a non-rigid end post composed of single double-sided stiffener as specified by EC3 [17] with length of $0.1 h_{w o}$ was considered, based on the negligible longitudinal stress induced in the corrugated webs [26]. Table 2 shows the dimensions considered in this study following the notations shown previously in Fig. 7 and with $\beta$ defined as the ratio between the longitudinal-to-inclined fold width ratio. As can be seen in Table 3, the ratios between the ultimate and the plastic bending moments $\left(M_{u l, F E} / M_{p l}\right)$ are given to guarantee that all the tapered BGCWs failed by shear away from the interaction with the flexural limit state by means of the development of flexural plastic hinges at their mid-spans. Only six BGCWs 
$\left(\mathrm{G} 15, \mathrm{G} 17, \mathrm{G} 18, \mathrm{G} 69, \mathrm{G} 71\right.$ and G72) were found to fail by flexure, $M_{u l, F E} / M_{p l} \geq 1.0$, so they were deleted from Table 3. The plastic bending moments were computed by $M_{p l}=b_{f} t_{f} f_{y}\left(h_{w 1}+t_{f}\right)$. From the table, it can be noticed that most of $M_{u l, F E} / M_{p l}$ ratios vary between 0.10 and 0.80 indicating that the flexural capacity limit state was still away to take place. The shear buckling relative slenderness of the corrugated webs $\left(\lambda_{s}=\sqrt{\tau_{y} / \tau_{I}}\right)$ was also calculated and added to the table, where the critical shear buckling stress $\left(\tau_{I}\right)$ was calculated according to Hassanein and Kharoob [14] by using:

$$
\begin{array}{ll}
\tau_{I}=\tau_{c r, I, 1} /(1+\tan \gamma) & \text { for Case I } \\
\tau_{I}=1.04 \tau_{c r, I, 1} /(1+\tan \gamma) & \text { for Case II }
\end{array}
$$

where $\tau_{y}$ and $\tau_{c r, I, 1}$ are the yield shear strength of the base material and the 1st-order interactive buckling strength proposed by Yi. et al [1], respectively, while $\gamma$ is angle of inclination of the flanges as previously defined. To allow the comparison with available design strength (Eq. 3) recommended by Hassanein and Kharoob [14] following Moon et al. [2] $\left(\tau_{u l, M}\right)$, the shear buckling relative slenderness of the corrugated webs was mainly considered in the range $0.6<\lambda_{s} \leq \sqrt{2}$.

$$
\frac{\tau_{u l, M}}{\tau_{y}}= \begin{cases}1.0 & : \lambda_{s} \leq 0.6 \\ 1-0.614\left(\lambda_{s}-0.6\right) & : 0.6<\lambda_{s} \leq \sqrt{2} \\ \frac{1}{\lambda_{s}^{2}} & : \sqrt{2}<\lambda_{s}\end{cases}
$$


Table 2: Profiles of corrugated steel webs of constructed bridges [1-2]

\begin{tabular}{|c|c|c|c|c|c|c|c|c|c|c|c|c|}
\hline $\begin{array}{c}\text { Bridge } \\
\text { name }\end{array}$ & $\begin{array}{c}b \\
{[\mathrm{~mm}]}\end{array}$ & $\begin{array}{c}d \\
{[\mathrm{~mm}]}\end{array}$ & $\begin{array}{c}c \\
{[\mathrm{~mm}]}\end{array}$ & $\begin{array}{c}h_{r} \\
{[\mathrm{~mm}]}\end{array}$ & $\begin{array}{c}t_{w} \\
{[\mathrm{~mm}]}\end{array}$ & $\begin{array}{c}h_{w} \\
{[\mathrm{~mm}]}\end{array}$ & $\begin{array}{c}s \\
{[\mathrm{~mm}]}\end{array}$ & $\begin{array}{c}q \\
{[\mathrm{~mm}]}\end{array}$ & $\begin{array}{c}\alpha \\
{\left[{ }^{\circ}\right]}\end{array}$ & $\beta$ & $w / h_{w} *$ & $h_{r} / t_{w}$ \\
\hline Maupré & 284 & 241 & 284 & 150 & 8 & 2650 & 1136 & 1050 & 31.9 & 1.00 & 0.11 & 18.8 \\
\hline Dole & 430 & 370 & 430 & 220 & 10 & 2546 & 1720 & 1600 & 30.7 & 1.00 & 0.17 & 22.0 \\
\hline
\end{tabular}

* $w$ is the bigger of $b$ and $c$

Table 3: Details of the tapered BGCWs - Case I and II of Maupré Bridge

\begin{tabular}{|c|c|c|c|c|c|c|c|c|c|c|c|c|}
\hline \multicolumn{4}{|c|}{ Geometrical properties } & \multicolumn{4}{|c|}{ Case I } & \multicolumn{4}{|c|}{ Case II } & \multirow[b]{2}{*}{$\frac{[12]}{[8]}$} \\
\hline $\begin{array}{c}h_{w o} \\
{[\mathrm{~mm}]}\end{array}$ & $\begin{array}{c}\gamma \\
{\left[^{\circ}\right]}\end{array}$ & $\begin{array}{c}t_{w} \\
{[\mathrm{~mm}]}\end{array}$ & $\frac{a}{h_{w 1}}$ & 过 & $\lambda_{s}$ & $\frac{M_{u l, F E}}{M_{p l}}$ & $\begin{array}{c}\tau_{u l, F E} \\
{[\mathrm{MPa}]}\end{array}$ & : & $\lambda_{s}$ & $\frac{M_{u l, F E}}{M_{p l}}$ & $\begin{array}{c}\tau_{u l, F E} \\
{[\mathrm{MPa}]}\end{array}$ & \\
\hline [1] & {$[2]$} & [3] & [4] & {$[5]$} & {$[6]$} & [7] & [8] & [9] & [10] & [11] & [12] & {$[13]$} \\
\hline 1944 & 10 & 4 & 1.26 & G1 & 1.25 & 0.13 & 115 & G55 & 1.23 & 0.17 & 157 & 1.37 \\
\hline 1667 & 10 & 4 & 1.89 & G2 & 1.25 & 0.17 & 123 & G56 & 1.23 & 0.18 & 126 & 1.02 \\
\hline 1389 & 10 & 4 & 2.52 & G3 & 1.25 & 0.20 & 128 & G57 & 1.23 & 0.22 & 140 & 1.09 \\
\hline 1944 & 10 & 6 & 1.26 & G4 & 0.91 & 0.24 & 143 & G58 & 0.90 & 0.25 & 152 & 1.06 \\
\hline 1667 & 10 & 6 & 1.89 & G5 & 0.91 & 0.30 & 141 & G59 & 0.90 & 0.33 & 153 & 1.09 \\
\hline 1389 & 10 & 6 & 2.52 & G6 & 0.91 & 0.37 & 156 & G60 & 0.90 & 0.39 & 165 & 1.06 \\
\hline 1944 & 10 & 8 & 1.26 & G7 & 0.75 & 0.38 & 171 & G61 & 0.74 & 0.42 & 192 & 1.12 \\
\hline 1667 & 10 & 8 & 1.89 & G8 & 0.75 & 0.48 & 170 & G62 & 0.74 & 0.51 & 178 & 1.05 \\
\hline 1389 & 10 & 8 & 2.52 & G9 & 0.75 & 0.54 & 172 & G63 & 0.74 & 0.56 & 178 & 1.03 \\
\hline 1944 & 10 & 10 & 1.26 & G10 & 0.65 & 0.55 & 199 & G64 & 0.64 & 0.57 & 207 & 1.04 \\
\hline 1667 & 10 & 10 & 1.89 & G11 & 0.65 & 0.65 & 182 & G65 & 0.64 & 0.73 & 207 & 1.14 \\
\hline 1389 & 10 & 10 & 2.52 & G12 & 0.65 & 0.72 & 182 & G66 & 0.64 & 0.77 & 196 & 1.08 \\
\hline 1944 & 10 & 12 & 1.26 & G13 & 0.59 & 0.79 & 237 & G67 & 0.60 & 0.71 & 213 & 0.90 \\
\hline 1667 & 10 & 12 & 1.89 & G14 & 0.59 & 0.91 & 213 & G68 & 0.58 & 0.93 & 218 & 1.02 \\
\hline 1944 & 10 & 14 & 1.26 & G16 & 0.54 & 0.83 & 216 & G70 & 0.55 & 0.86 & 222 & 1.03 \\
\hline 1656 & 15 & 4 & 1.26 & G19 & 1.30 & 0.12 & 131 & G73 & 1.29 & 0.13 & 138 & 1.05 \\
\hline 1233 & 15 & 4 & 1.89 & G20 & 1.30 & 0.14 & 133 & G74 & 1.29 & 0.15 & 147 & 1.11 \\
\hline 811 & 15 & 4 & 2.52 & G21 & 1.30 & 0.16 & 172 & G75 & 1.29 & 0.18 & 193 & 1.12 \\
\hline 1656 & 15 & 6 & 1.26 & G22 & 0.95 & 0.20 & 145 & G76 & 0.95 & 0.25 & 176 & 1.21 \\
\hline 1233 & 15 & 6 & 1.89 & G23 & 0.95 & 0.25 & 157 & G77 & 0.95 & 0.27 & 172 & 1.10 \\
\hline 811 & 15 & 6 & 2.52 & G24 & 0.95 & 0.28 & 200 & G78 & 0.95 & 0.31 & 222 & 1.11 \\
\hline 1656 & 15 & 8 & 1.26 & G25 & 0.78 & 0.31 & 165 & G79 & 0.78 & 0.35 & 184 & 1.12 \\
\hline 1233 & 15 & 8 & 1.89 & G26 & 0.78 & 0.37 & 175 & G80 & 0.78 & 0.40 & 189 & 1.08 \\
\hline 811 & 15 & 8 & 2.52 & G27 & 0.78 & 0.41 & 222 & G81 & 0.78 & 0.44 & 240 & 1.08 \\
\hline 1656 & 15 & 10 & 1.26 & G28 & 0.68 & 0.44 & 189 & G82 & 0.69 & 0.49 & 210 & 1.11 \\
\hline 1233 & 15 & 10 & 1.89 & G29 & 0.68 & 0.51 & 195 & G83 & 0.69 & 0.54 & 206 & 1.06 \\
\hline
\end{tabular}




\begin{tabular}{|c|c|c|c|c|c|c|c|c|c|c|c|c|}
\hline \multicolumn{4}{|c|}{ Geometrical properties } & \multicolumn{4}{|c|}{ Case I } & \multicolumn{4}{|c|}{ Case II } & \multirow[b]{2}{*}{$\frac{[12]}{[8]}$} \\
\hline $\begin{array}{c}h_{w o} \\
{[\mathrm{~mm}]}\end{array}$ & $\begin{array}{c}\gamma \\
{\left[{ }^{\circ}\right]}\end{array}$ & $\begin{array}{c}t_{w} \\
{[\mathrm{~mm}]}\end{array}$ & $\frac{a}{h_{w 1}}$ & 包 & $\lambda_{s}$ & $\frac{M_{u l, F E}}{M_{p l}}$ & $\begin{array}{r}\tau_{u l, F E} \\
{[\mathrm{MPa}]}\end{array}$ & $\frac{\dot{\theta}}{\stackrel{0}{0}}$ & $\lambda_{s}$ & $\frac{M_{u l, F E}}{M_{p l}}$ & $\begin{array}{c}\tau_{u l, F E} \\
{[\mathrm{MPa}]}\end{array}$ & \\
\hline [1] & [2] & [3] & {$[4]$} & [5] & {$[6]$} & [7] & [8] & [9] & {$[10]$} & [11] & {$[12]$} & {$[13]$} \\
\hline 811 & 15 & 10 & 2.52 & G30 & 0.68 & 0.49 & 214 & G84 & 0.69 & 0.65 & 281 & 1.31 \\
\hline 1656 & 15 & 12 & 1.26 & G31 & 0.61 & 0.62 & 222 & G85 & 0.62 & 0.63 & 224 & 1.01 \\
\hline 1233 & 15 & 12 & 1.89 & G32 & 0.61 & 0.63 & 201 & G86 & 0.62 & 0.71 & 225 & 1.12 \\
\hline 811 & 15 & 12 & 2.52 & G33 & 0.61 & 0.63 & 226 & G87 & 0.62 & 0.68 & 247 & 1.09 \\
\hline 1656 & 15 & 14 & 1.26 & G34 & 0.57 & 0.75 & 229 & G88 & 0.58 & 0.74 & 226 & 0.99 \\
\hline 1233 & 15 & 14 & 1.89 & G35 & 0.57 & 0.75 & 205 & G89 & 0.58 & 0.90 & 245 & 1.20 \\
\hline 811 & 15 & 14 & 2.52 & G36 & 0.57 & 0.84 & 260 & G90 & 0.58 & 0.91 & 283 & 1.09 \\
\hline 1353 & 20 & 4 & 1.26 & G37 & 1.35 & 0.11 & 146 & G91 & 1.34 & 0.12 & 151 & 1.03 \\
\hline 779 & 20 & 4 & 1.89 & G38 & 1.35 & 0.13 & 189 & G92 & 1.34 & 0.14 & 207 & 1.10 \\
\hline 1353 & 20 & 6 & 1.26 & G39 & 0.98 & 0.20 & 176 & G93 & 0.99 & 0.19 & 169 & 0.96 \\
\hline 779 & 20 & 6 & 1.89 & G40 & 0.98 & 0.22 & 219 & G94 & 0.99 & 0.25 & 250 & 1.14 \\
\hline 1353 & 20 & 8 & 1.26 & G41 & 0.81 & 0.30 & 196 & G95 & 0.81 & 0.30 & 198 & 1.01 \\
\hline 779 & 20 & 8 & 1.89 & G42 & 0.81 & 0.32 & 243 & G96 & 0.81 & 0.36 & 271 & 1.12 \\
\hline 1353 & 20 & 10 & 1.26 & G43 & 0.70 & 0.40 & 206 & G97 & 0.71 & 0.42 & 218 & 1.06 \\
\hline 779 & 20 & 10 & 1.89 & G44 & 0.70 & 0.32 & 194 & G98 & 0.71 & 0.48 & 288 & 1.48 \\
\hline 1353 & 20 & 12 & 1.26 & G45 & 0.64 & 0.51 & 220 & G99 & 0.64 & 0.54 & 233 & 1.06 \\
\hline 779 & 20 & 12 & 1.89 & G46 & 0.64 & 0.48 & 242 & G100 & 0.64 & 0.60 & 301 & 1.24 \\
\hline 1353 & 20 & 14 & 1.26 & G47 & 0.59 & 0.59 & 220 & G101 & 0.60 & 0.67 & 247 & 1.12 \\
\hline 779 & 20 & 14 & 1.89 & G48 & 0.59 & 0.63 & 272 & G102 & 0.60 & 0.71 & 303 & 1.11 \\
\hline 1030 & 25 & 4 & 1.26 & G49 & 1.40 & 0.10 & 163 & G103 & 1.39 & 0.11 & 181 & 1.11 \\
\hline 1030 & 25 & 6 & 1.26 & G50 & 1.02 & 0.16 & 184 & G104 & 1.02 & 0.18 & 204 & 1.11 \\
\hline 1030 & 25 & 8 & 1.26 & G51 & 0.84 & 0.23 & 200 & G105 & 0.84 & 0.26 & 226 & 1.13 \\
\hline 1030 & 25 & 10 & 1.26 & G52 & 0.73 & 0.45 & 307 & G106 & 0.74 & 0.42 & 290 & 0.94 \\
\hline 1030 & 25 & 12 & 1.26 & G53 & 0.66 & 0.41 & 233 & G107 & 0.67 & 0.44 & 253 & 1.09 \\
\hline 1030 & 25 & 14 & 1.26 & G54 & 0.61 & 0.50 & 246 & G108 & 0.62 & 0.60 & 291 & 1.18 \\
\hline \multicolumn{12}{|c|}{ Mean } & 1.10 \\
\hline \multicolumn{12}{|c|}{ Standard deviation } & 0.098 \\
\hline
\end{tabular}

\section{RESULTS AND DISCUSSION}

\subsection{General}

The first positive eigenmode was found to be the first one in all BGCWs with Case I, while for those of Case II it was not. Hence, it should be chosen even within the 30 first modes. 
Almost all girders failed by interactive modes with the exception of girders with higher $t_{w}$ values which failed globally. Generally, the buckling was not restricted to one panel, but it goes across the fold line and extended to the neighbouring panel, as can be seen in Fig. 11 . This figure shows the deformed shapes at the ultimate loads as well as the stress contours for G2 and G56 which are typical BGCWs but with different positions within the continuous two-span BGCWs. A major difference between the current tapered BGCWs and those with flat webs [13] is that the former girders fail without the propagation of shear plastic hinges at their top flanges. This is attributed to the significant out-of-plane stiffness of the BGCWs which eliminates differential shear deformation between the top and bottom flanges. On the other hand, regions with the gray contour in Fig. 11 are the locations plasticised by exceeding the yield strength of the material (355MPa), which are surrounded by yielded portions in red. It can be observed that the width of the developed tension band in Case I girders is wider than that generated in corresponding Case II girders. This was noticed for the different pairs of this paper. Regarding the strength of both types of girders, it can be noticed from Table 3 that girders with Case II carry higher shear loads compared to Case I bridges with an average ratio of 1.10. Moreover, the results indicate that ultimate shear capacity seems to be independent on girder's $a / h_{w 1}$ ratio similar to that previously noticed by Luo and Edlund [27] but for the case of prismatic girders.

It can also observed from the table that increasing the thickness raises the shear capacity considerably for different values of $\gamma$. However, it is well known that the in modern construction, the demand of light-weight as well as high-performance structures is of importance. Hence, it becomes essential to examine the increase in the strength $\left(S_{t_{w}-t_{w}=4 m m}\right)$ relative to the increase in the weight $\left(W_{t_{w}-t_{w}=4 m m}\right)$ of the tapered BGCWs gained by 
increasing the value of $t_{w}$. This is made, herein on sample results having the same aspect ratios, as can be seen in Table 4 by considering the values of $t_{w}=4 \mathrm{~mm}$ as a reference. From the table, it can be seen that a large increase in the weight of the BGCWs associated by increasing $t_{w}$ is accompanied by a relatively slight increase in the strength, making the tapered BGCWs with smaller $t_{w}$ more effective; for example, relative increase of the strength of G18 $\left(t_{w}=14 \mathrm{~mm}\right)$ compared to $\mathrm{G} 3\left(t_{w}=4 \mathrm{~mm}\right)$ is $49 \%$ as a result of increasing the weight by $250 \%$. This highlights the advantage of using two corrugated web plates in the BGCWs, as suggested by Kim et al. [28] and shown herein in Fig. 12, with small $t_{w}$ instead of the conventional BGCWs with single webs of large $t_{w}$ values. This web corrugation [28], to the authors' best knowledge, has never been studied under shear neither in prismatic nor in tapered girders, and hence it worth future investigation.

a) Case I

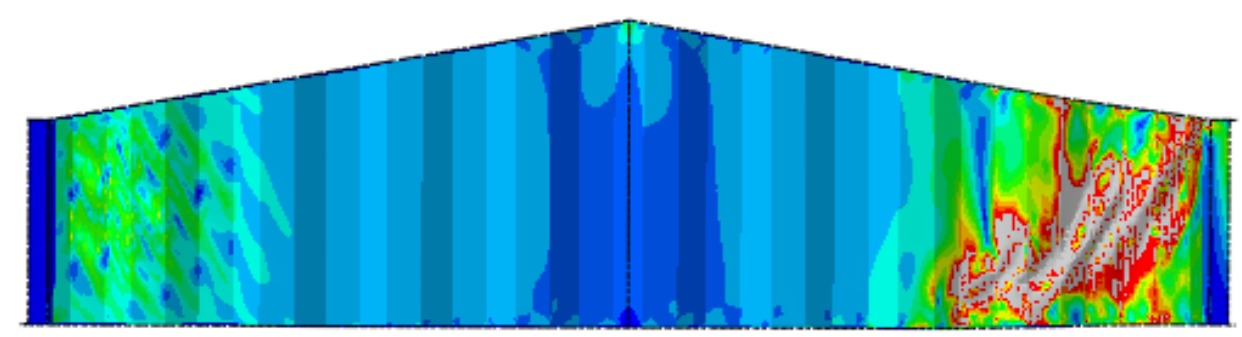

b) Case II

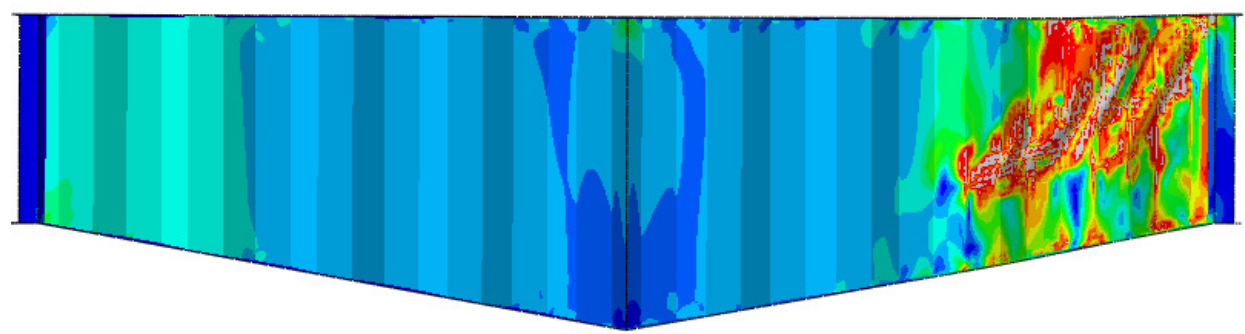

Fig. 11: Deformed shape and stress contour for typical BGCWs with different cases: (a) G2 and (b) G56 
Table 4: Variation of strength against the variation of the weight for sample results

\begin{tabular}{|c|c|c|c|c|}
\hline \multicolumn{2}{|c|}{ Case I } & \multicolumn{2}{c|}{ Case II } & \multirow{2}{*}{$W_{t_{w}-t_{w}=4 m m}$} \\
\cline { 1 - 4 } Girder & $S_{t_{w}-t_{w}=4 m m}$ & Girder & $S_{t_{w}-t_{w}=4 m m}$ & \\
\hline G3 & 0.00 & G57 & 0.00 & 0.00 \\
\hline G6 & 0.22 & G60 & 0.18 & 0.50 \\
\hline G9 & 0.34 & G63 & 0.27 & 1.00 \\
\hline G12 & 0.42 & G66 & 0.40 & 1.50 \\
\hline G15 & 0.64 & G69 & 0.55 & 2.00 \\
\hline G18 & 0.49 & G72 & 0.39 & 2.50 \\
\hline
\end{tabular}

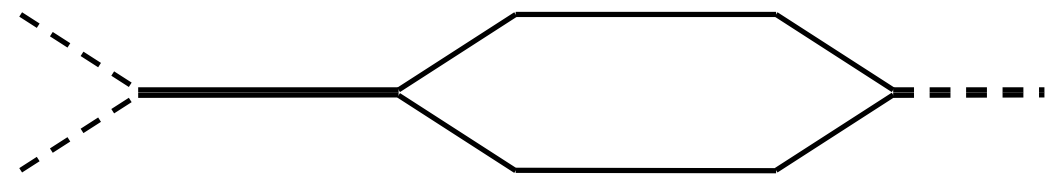

Fig. 12: Corrugation configuration using two web plates

\subsection{Effect of inclined flange angle}

One of the most factors affecting the behaviour of the tapered BGCWs is the inclined flange angle $(\gamma)$, which changes the taper ratio $\left(h_{w 1} / h_{w o}\right)$ of the girders. It was found that this ratio $\left(h_{w 1} / h_{w o}\right)$ does not exceed 4 in a large proportion of existing structures [29]. Hence, the maximum value of the taper ratio was 3.20 for the case of $\gamma=25^{\circ}$ and $a=6300 \mathrm{~mm}$. In this sub-section, the influence of $\gamma$ (measured relative to horizontal projection) on the ultimate shear strength $\left(V_{u l, F E}\right)$ and the load-mid-span deflection response of tapered BGCWs under shear loading was studied considering the same ratios of $a / h_{w 1}$. Herein, four values of $\gamma(10$, 15,20 and $25^{\circ}$ ) were considered. The applied load-mid-span vertical deflection relationships for sample results are provided in Fig. 13. The figure shows the relationships for girders G13, G31, G45 and G53 of Case I-Maupré Bridge and G67, G85, G99 and G107 of Case IIMaupré Bridge which have inclined flange angles of 10, 15, 20 and $25^{\circ}$, respectively. It can be seen that increasing the inclined flange angle $(\gamma)$, with depth $h_{w 1}$ being fixed, significantly reduces the ultimate shear strength of the tapered BGCWs, while the initial stiffness remains 
approximately the same. This is because the depth of the critical section of the girder $\left(h_{w o}\right)$ minimises with increasing $\gamma$. Moreover, it can be observed that all tapered BGCWs fail a brittle manner irrespective of the value of $\gamma$ with a considerable residual strength remaining after failure. It can additionally be observed that the loading capacity of the webs at the descending stage is almost independent of the value of $\gamma$. Fig. 14 compares the stress distribution at the ultimate shear loads of the same selected girders presented previously in Fig. 13. As can be seen, the portions exceeding the yield strength, near the supports, extend in a wider range from the shear span by increasing the angle of inclination $(\gamma)$ with fixing the $\operatorname{depth} h_{w 1}$.

(a)

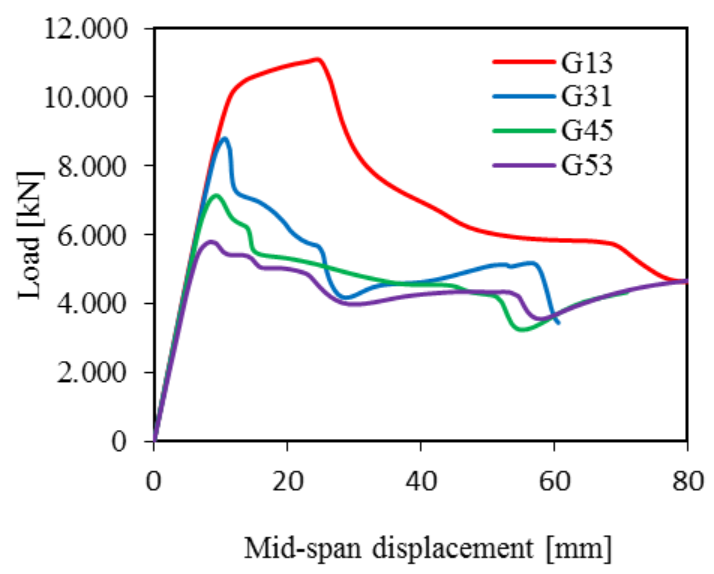

(b)

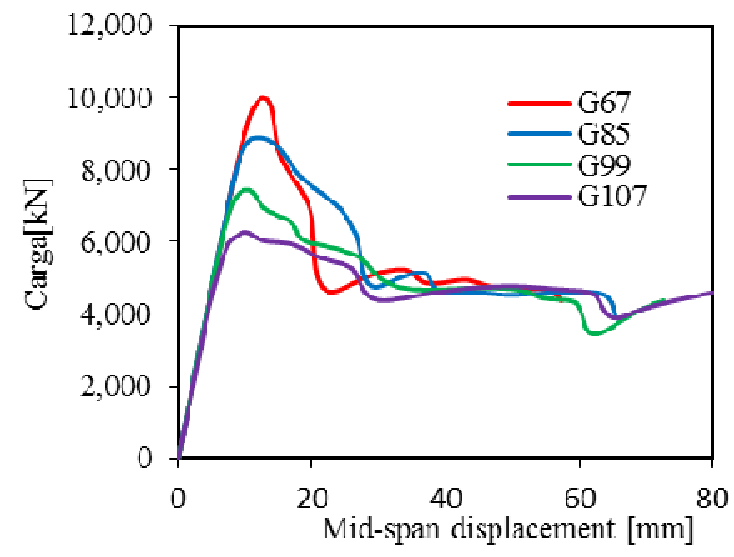

Fig. 13: Load-mid-span deflection for girders of typical tapered BGCWs: (a) Case I and (b) Case II

\subsection{Comparison with design strength}

In this sub-section, a comparison between the design strength (Eq. 3) and FE normalised strengths $\left(\tau_{u l, F E} / \tau_{y}\right)$ varying with relative slenderness range is carried out. Fig. 15 represents a sample of results for bridges with Case I (Fig. 15(a)) and Case II (Fig. 15(b)) with $a=3150 \mathrm{~mm}$ and with different inclination angles $(\gamma)$. The FE strengths in their majority are 
close or a bit greater than the design strength values, which it means that the values proposed Eq. 3 are generally conservative. Furthermore, the prediction is conservative with different values of $\gamma$. As can be seen, the design model provides a lower bound for girders with Case II because they own higher FE strengths compared with those of Case I, as shown previously in Section 4.1. 
G13: $\gamma=10^{\circ}$

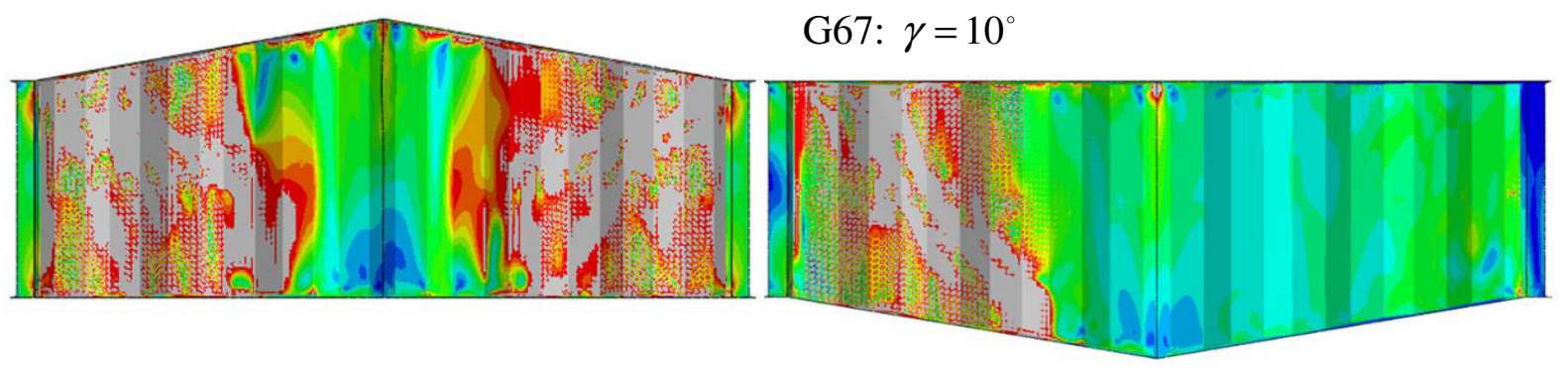

G31: $\gamma=15^{\circ}$
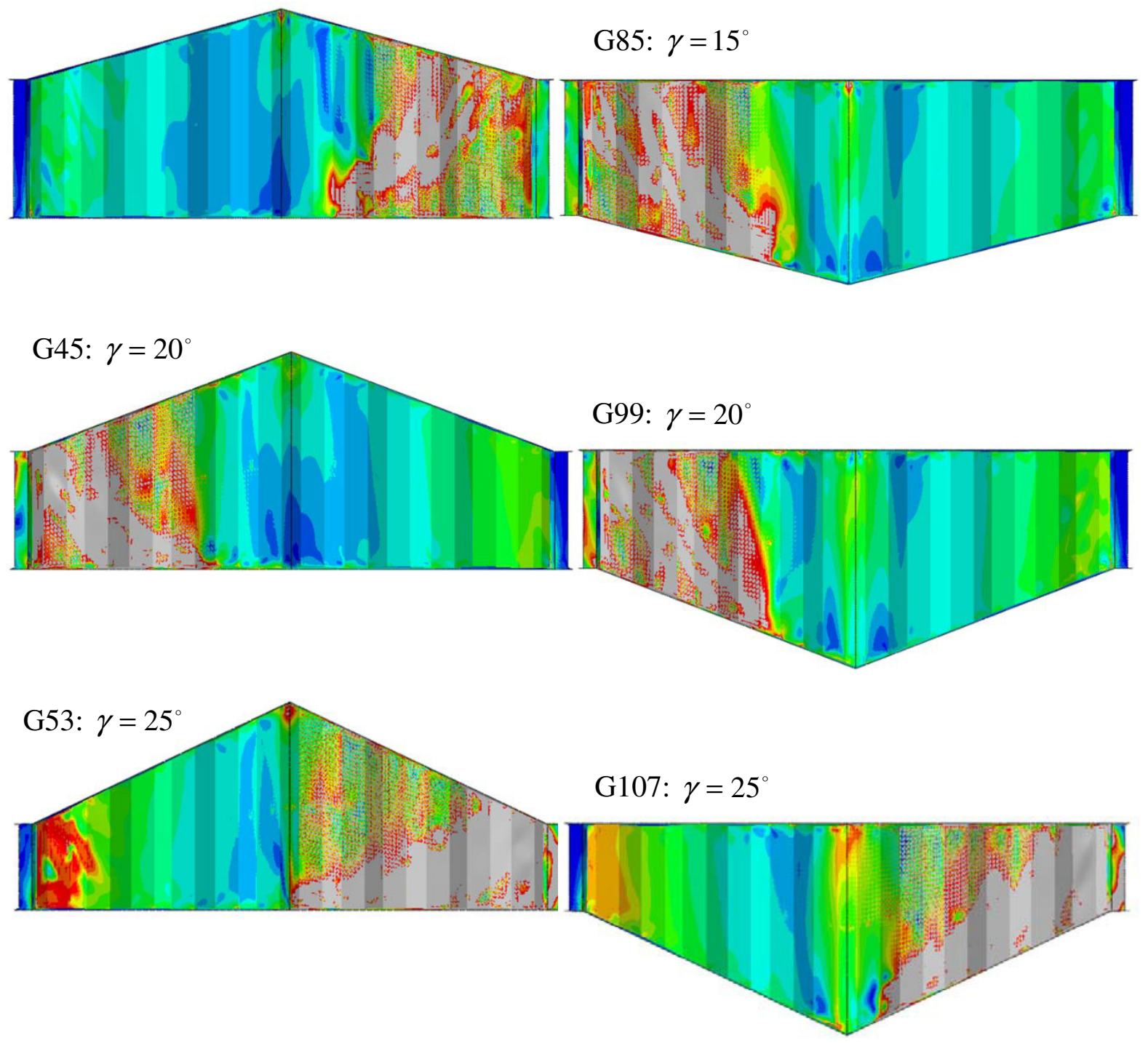

Fig. 14: Stress contour representing the effect of varying $\gamma$ 


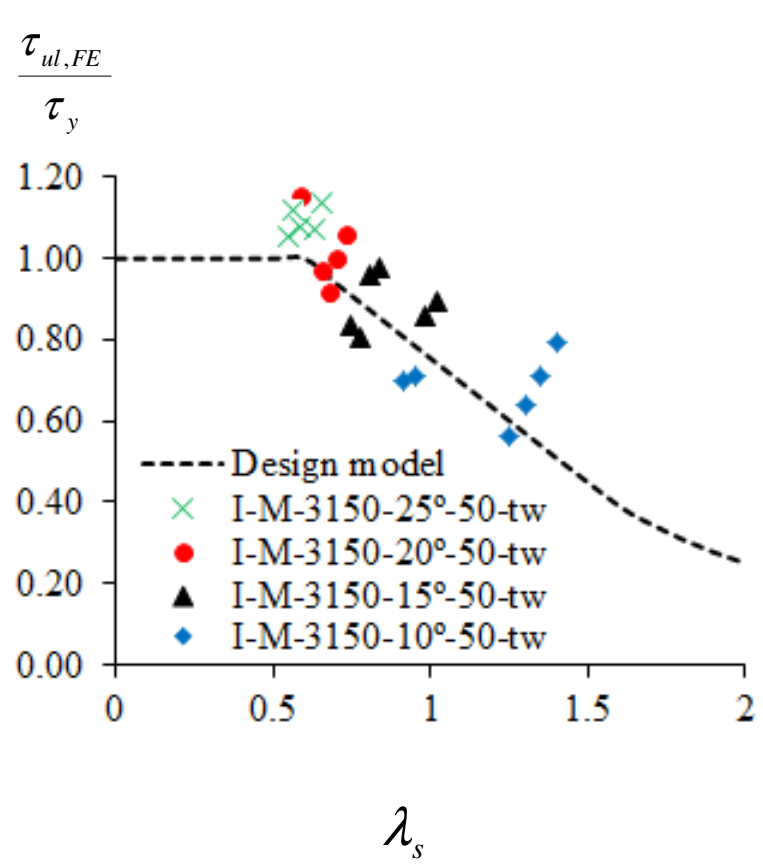

(a) Case I

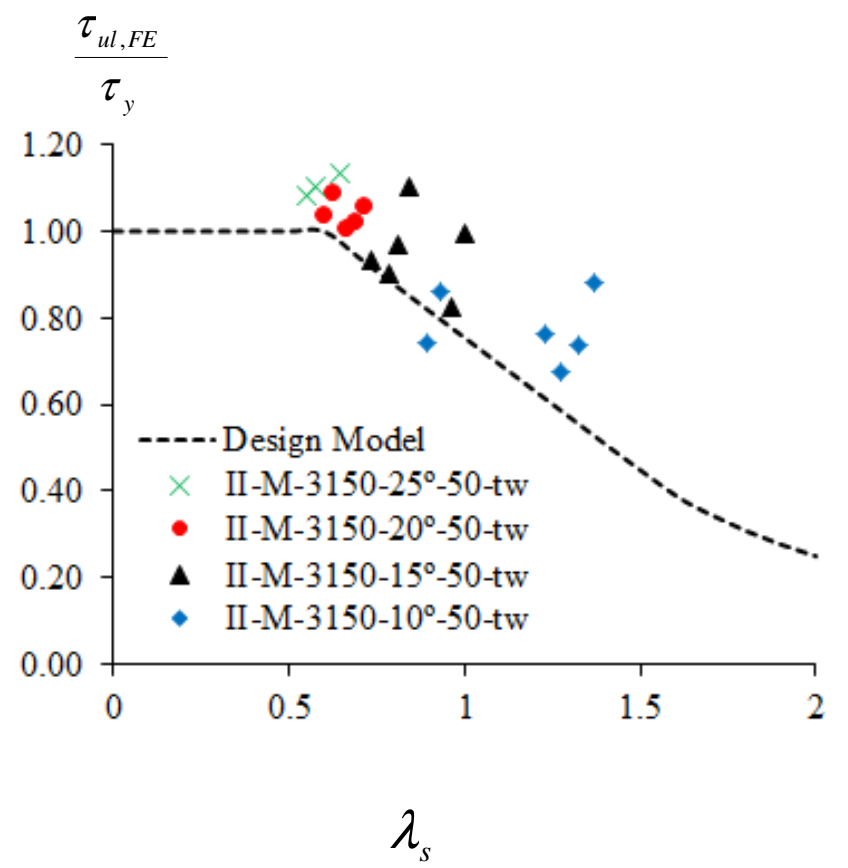

(b) Case II

Fig. 15: Comparison between design and FE strengths with different relative slenderness range: (a) Case I and (b) Case II of Maupré Bridge

\section{EFFECT OF DIFFERENT CORRUGATION DIMENSIONS}

\subsection{General}

Studying different corrugation dimensions may help in understanding their effect on the shear force resistance of the tapered BGCWs. Table 5 presents the dimension of 16 girders which were additionally analysed, where it can be noticed that the angle between the longitudinal and inclined sub-panels $(\alpha)$ varies between $7^{\circ}$ and $90^{\circ}$. This may extend the available design method to ordinary structures rather than bridges. Figs. 16 and 17 show the profile shapes of interest to this extended study, at which it can be noticed that corrugated webs with dimensions near to flat webs are investigated. The analysis considered merely $\gamma$ of $15^{\circ}$. The FE results of $\tau_{u l, F E}$ are presented in Table 6. It is possible to notice that as the angle $(\alpha)$ 
between sub-panels decreases, the ultimate shear $\left(V_{u l, F E}\right)$ decreases because the rigidity of the web decreases. It is worth pointing that the web with lower angle among panels has the global buckling behaviour as flat panel, as can be seen in Fig. 18 which shows the deformed shape of girder G174. This conclusion for the case of tapered girders accords with the results of Linder and Huang [30] on prismatic girders whom suggested that the corrugation angle should not be less than $30^{\circ}$ for the corrugation sub-panels to provide adequate support to one another along the fold lines to mobilized the shear capacity. The FE strengths were also compared with design strengths in Fig. 19 which shows good agreement.

Table 5: Dimensions from different profile shapes

\begin{tabular}{|c|c|c|c|c|c|c|c|}
\hline Girder & $b[\mathrm{~mm}]$ & $d[\mathrm{~mm}]$ & $c[\mathrm{~mm}]$ & $q[\mathrm{~mm}]$ & $s[\mathrm{~mm}]$ & $h_{r}[\mathrm{~mm}]$ & $\alpha\left[^{\circ}\right]$ \\
\hline G163 & 525.0 & 0.00 & 150.0 & 1050.0 & 1350.0 & 150.0 & 90.0 \\
\hline G164 & 404.5 & 120.5 & 192.4 & 1050.0 & 1193.8 & 150.0 & 51.2 \\
\hline G165 & 284.0 & 241.0 & 256.7 & 1050.0 & 1081.4 & 90.0 & 20.5 \\
\hline G166 & 284.0 & 241.0 & 242.9 & 1050.0 & 1053.7 & 30.0 & 7.1 \\
\hline G167 & 525.0 & 0.00 & 150.0 & 1050.0 & 1350.0 & 150.0 & 90.0 \\
\hline G168 & 404.5 & 120.5 & 192.4 & 1050.0 & 1193.8 & 150.0 & 51.2 \\
\hline G169 & 284.0 & 241.0 & 256.7 & 1050.0 & 1081.4 & 90.0 & 20.5 \\
\hline G170 & 284.0 & 241.0 & 242.9 & 1050.0 & 1053.7 & 30.0 & 7.1 \\
\hline G171 & 800.0 & 0.00 & 220.0 & 1600.0 & 2040.0 & 220.0 & 90.0 \\
\hline G172 & 615.0 & 185.0 & 287.9 & 1600.0 & 1805.8 & 220.0 & 50.0 \\
\hline G173 & 430.0 & 370.0 & 402.0 & 1600.0 & 1664.0 & 157.0 & 23.0 \\
\hline G174 & 430.0 & 370.0 & 375.3 & 1600.0 & 1610.6 & 63.0 & 9.7 \\
\hline G175 & 800.0 & 0.00 & 220.0 & 1600.0 & 2040.0 & 220.0 & 90.0 \\
\hline G176 & 615.0 & 185.0 & 287.9 & 1600.0 & 1805.8 & 220.0 & 50.0 \\
\hline G177 & 430.0 & 370.0 & 402.0 & 1600.0 & 1664.0 & 157.0 & 23.0 \\
\hline G178 & 430.0 & 370.0 & 375.3 & 1600.0 & 1610.6 & 63.0 & 9.7 \\
\hline
\end{tabular}




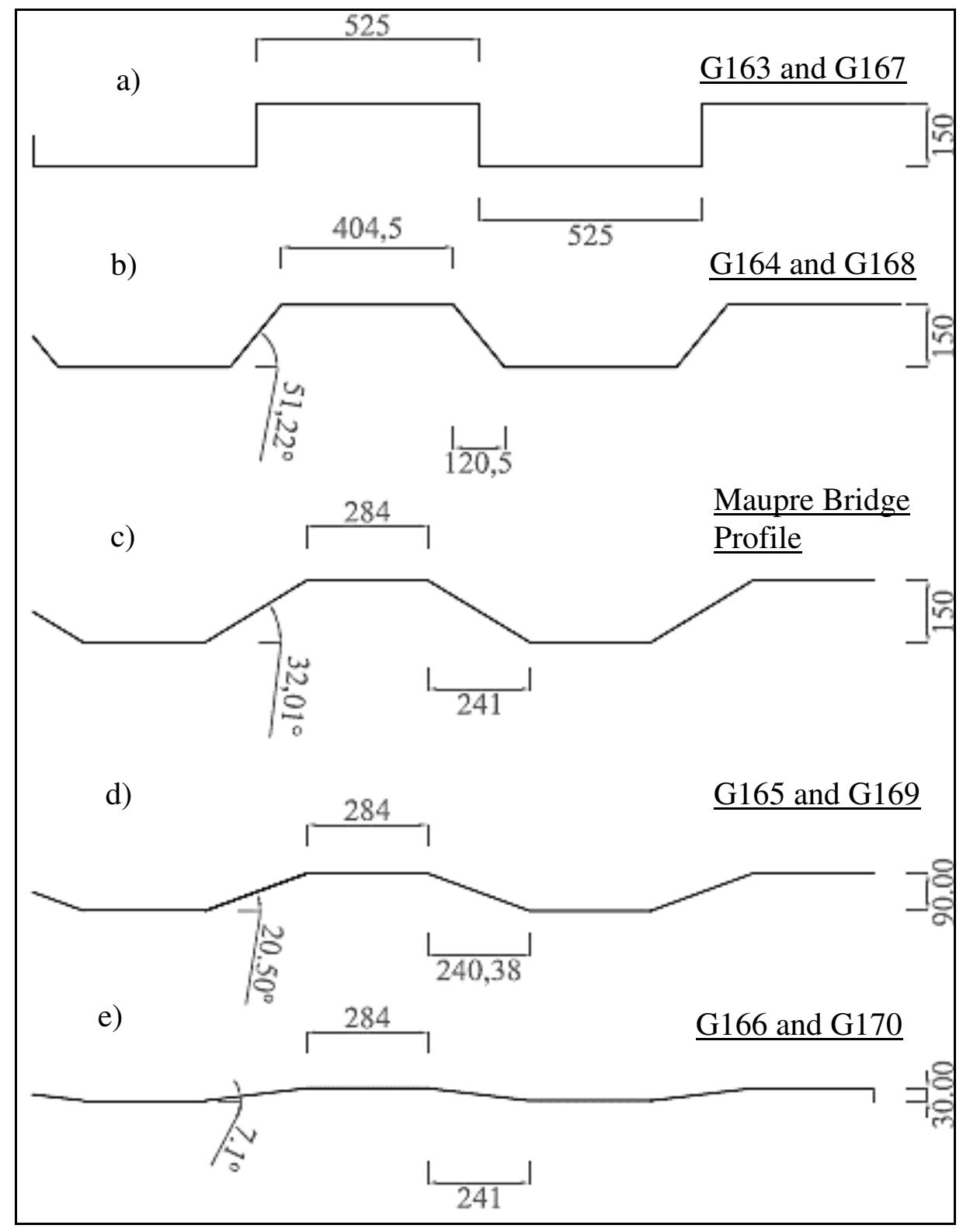

Fig. 16: Different profiles based on Maupré Bridge Profile 


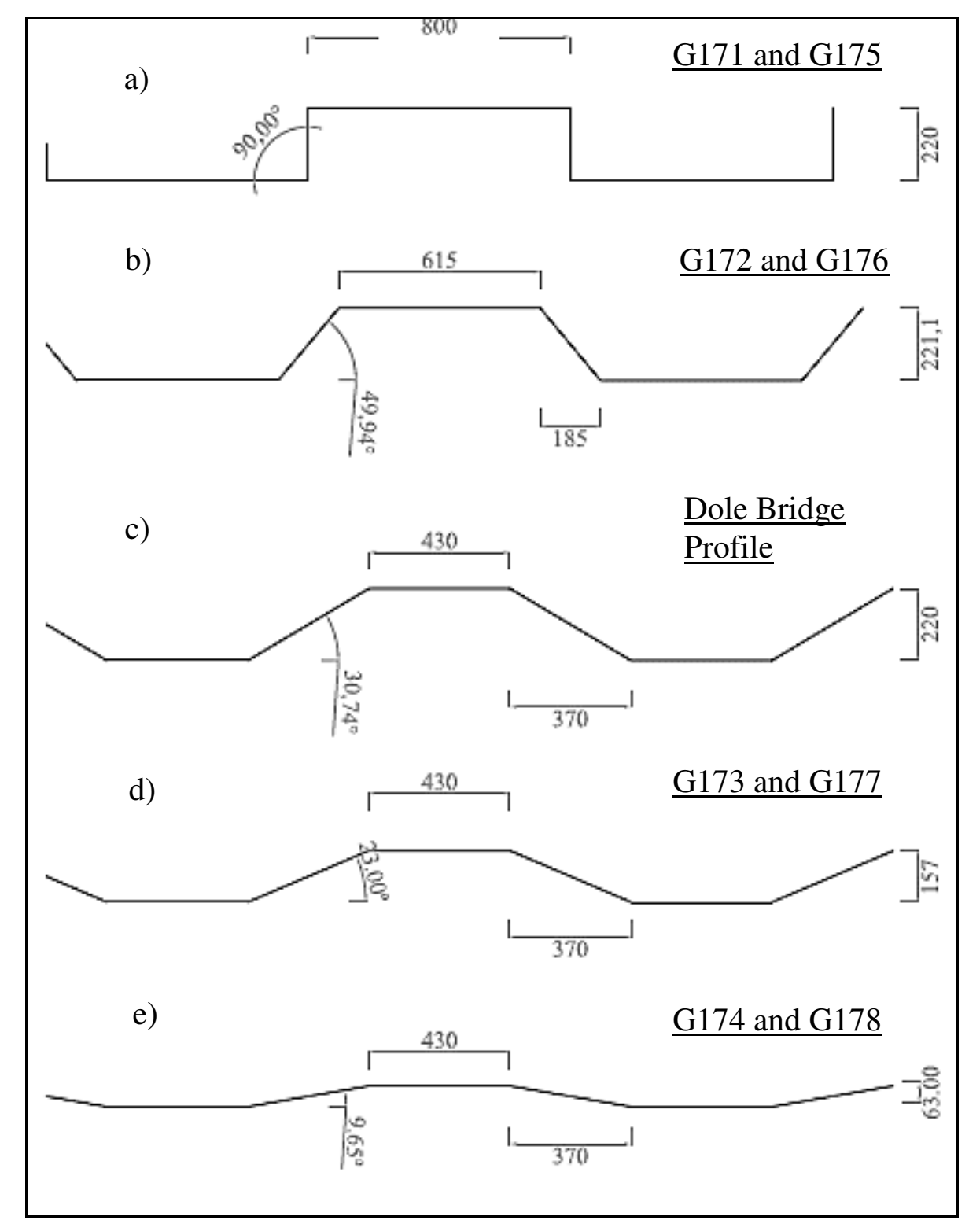

Fig. 17: Different profiles based on Dole Bridge Profile

Table 6: FE results of $\tau_{u l, F E}$ of different profile shapes

\begin{tabular}{|c|c|c|c|c|c|c|c|c|c|c|c|}
\hline 节 & $\begin{array}{c}h_{w o} \\
{[\mathrm{~mm}]}\end{array}$ & $\begin{array}{c}h_{\text {名 }} \\
{[\mathrm{mm}]}\end{array}$ & $\begin{array}{c}t_{f} \\
{[\mathrm{~mm}]}\end{array}$ & $\gamma_{\circ}$ & $\begin{array}{c}t_{w} \\
{[\mathrm{~mm}]}\end{array}$ & $\begin{array}{c}a \\
{[\mathrm{~mm}]}\end{array}$ & $a / h_{w 1}$ & $\lambda_{s}$ & $\frac{M_{u l, F E}}{M_{p l}}$ & $\begin{array}{c}V_{u l, F E} \\
{[\mathrm{kN}]}\end{array}$ & $\begin{array}{c}\tau_{u l, F E} \\
{[\mathrm{MPa}]}\end{array}$ \\
\hline G163 & 1656 & 2500 & 50 & 15 & 6 & 3150 & 1.26 & 1.49 & 0.24 & 1664 & 168 \\
\hline G164 & 1656 & 2500 & 50 & 15 & 6 & 3150 & 1.26 & 1.20 & 0.23 & 1645 & 166 \\
\hline G165 & 1656 & 2500 & 50 & 15 & 6 & 3150 & 1.26 & 1.13 & 0.20 & 1435 & 144 \\
\hline G166 & 1656 & 2500 & 50 & 15 & 6 & 3150 & 1.26 & 2.07 & 0.23 & 1596 & 161 \\
\hline G167 & 1656 & 2500 & 50 & 15 & 12 & 3150 & 1.26 & 0.82 & 0.30 & 2103 & 106 \\
\hline G168 & 1656 & 2500 & 50 & 15 & 12 & 3150 & 1.26 & 0.70 & 0.60 & 4242 & 214 \\
\hline G169 & 1656 & 2500 & 50 & 15 & 12 & 3150 & 1.26 & 0.80 & 0.54 & 3810 & 192 \\
\hline G170 & 1656 & 2500 & 50 & 15 & 12 & 3150 & 1.26 & 1.66 & 0.48 & 3385 & 170 \\
\hline
\end{tabular}




\begin{tabular}{|c|c|c|c|c|c|c|c|c|c|c|c|}
\hline G171 & 1642 & 2500 & 50 & 15 & 6 & 3200 & 1.28 & 2.17 & 0.21 & 1423 & 144 \\
\hline G172 & 1642 & 2500 & 50 & 15 & 6 & 3200 & 1.28 & 1.69 & 0.20 & 1408 & 143 \\
\hline G173 & 1642 & 2500 & 50 & 15 & 6 & 3200 & 1.28 & 1.27 & 0.20 & 1412 & 143 \\
\hline G174 & 1642 & 2500 & 50 & 15 & 6 & 3200 & 1.28 & 1.59 & 0.12 & 824 & 84 \\
\hline G175 & 1642 & 2500 & 50 & 15 & 12 & 3200 & 1.28 & 1.11 & 0.39 & 2712 & 138 \\
\hline G176 & 1642 & 2500 & 50 & 15 & 12 & 3200 & 1.28 & 0.89 & 0.34 & 2371 & 120 \\
\hline G177 & 1642 & 2500 & 50 & 15 & 12 & 3200 & 1.28 & 0.74 & 0.52 & 3587 & 182 \\
\hline G178 & 1642 & 2500 & 50 & 15 & 12 & 3200 & 1.28 & 1.09 & 0.53 & 3681 & 187 \\
\hline
\end{tabular}

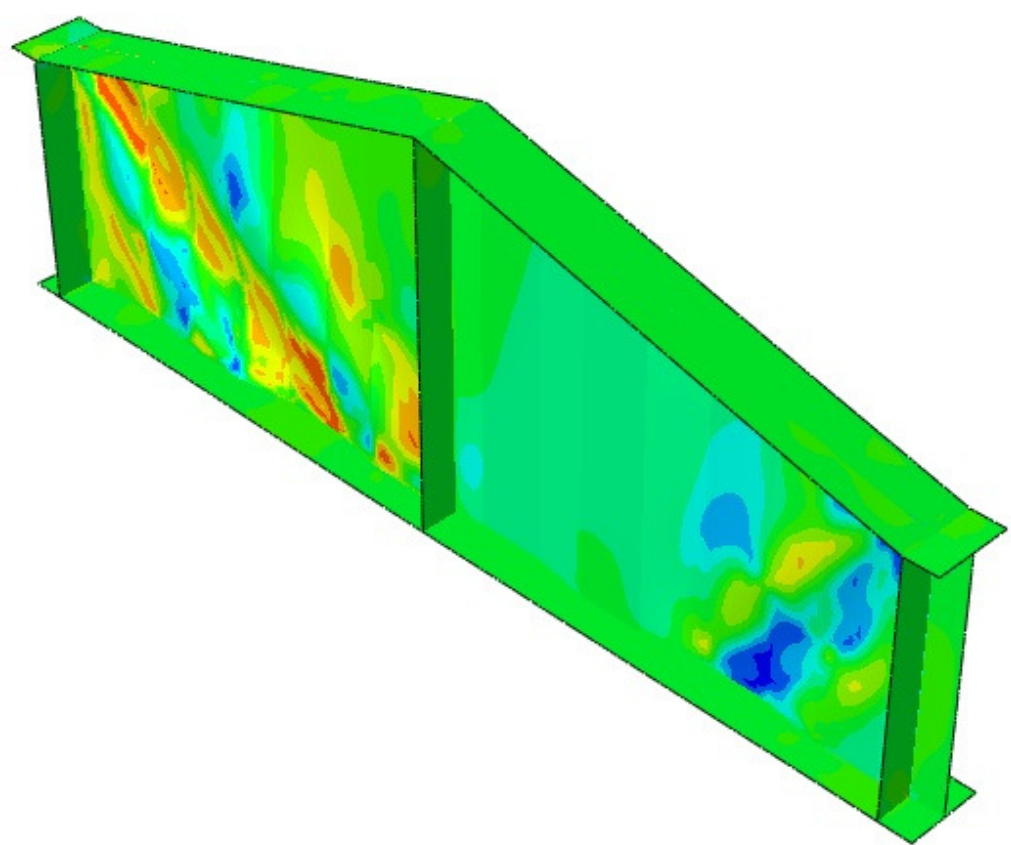

Fig. 18: Deformed shape of G174

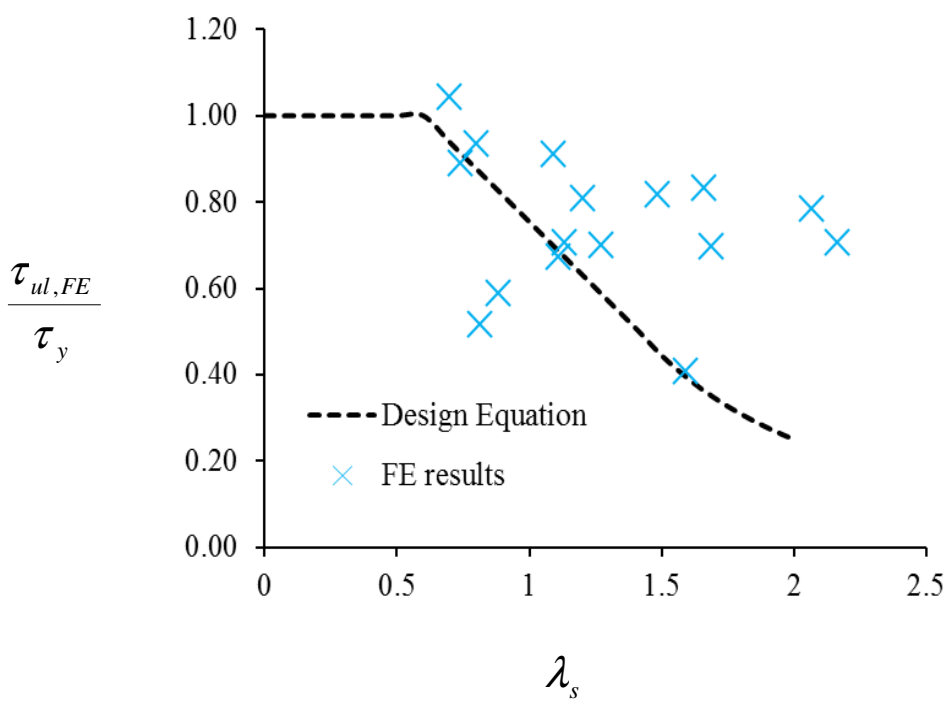

Fig. 19: Design model versus relative slenderness - Case I from different profiles 


\subsection{Checking the design model using all current results}

Fig. 20 presents the FE strength relative to the yield strength drawn against the relative slenderness of all girders generated in the current paper. The design model of Eq. 3 was also added to the figure, from which large variation of the results can be seen compared to Eq. 3 . However, statistics values for the relative strengths with the different slenderness parameter ranges of Eq. 3, are given in Table 7. Generally, the first $\left(\lambda_{s} \leq 0.6\right)$ and second $\left(0.6<\lambda_{s} \leq \sqrt{2}\right)$ regions are suitably predicted but with some unconservative results, while the design model provides lower envelop in the third region with $\lambda_{s}>\sqrt{2}$. Overall, it can be concluded that the design model yields appropriate results along the three behavioural stages for the tapered BGCWs for different applications.

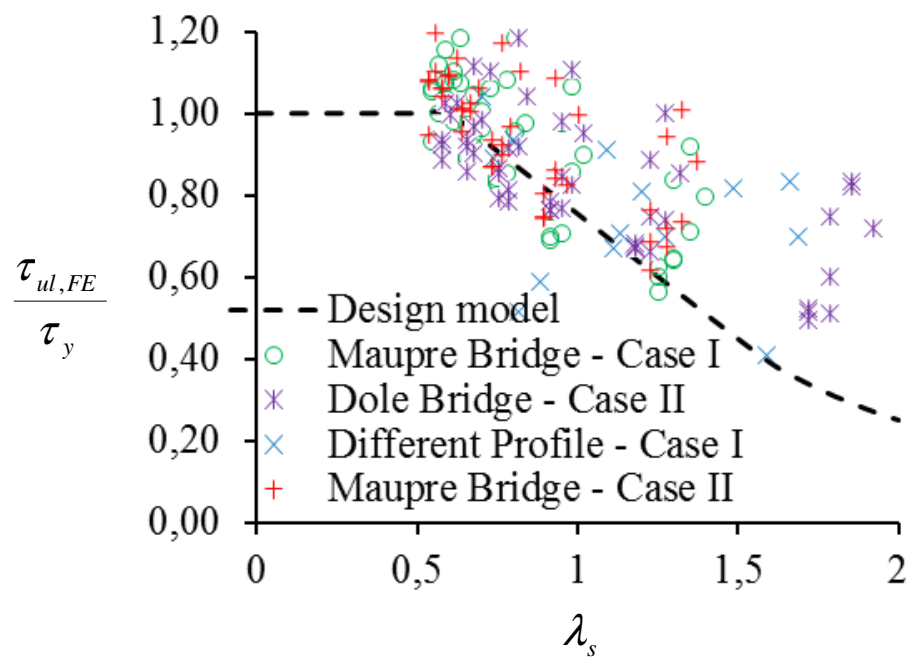

Fig. 20: Available design model versus relative slenderness - All Data

Table 7: Statistics values for the relative strengths with the different relative slenderness ranges of Eq. 3

\begin{tabular}{|c|c|}
\cline { 2 - 2 } \multicolumn{1}{c|}{} & $\tau_{u l, F E} / \tau_{y}$ \\
\hline$\lambda_{s} \leq 0.6$ & \\
\hline Ave & 1.11 \\
\hline COV & 0.19 \\
\hline
\end{tabular}




\begin{tabular}{|c|c|}
\hline $0.6<\lambda_{s} \leq \sqrt{2}$ & \\
\hline Ave & 0.93 \\
\hline COV & 0.20 \\
\hline$\sqrt{2}<\lambda_{s}$ & \\
\hline Ave & 0.67 \\
\hline COV & 0.15 \\
\hline
\end{tabular}

\section{SUMMARY AND CONCLUSIONS}

Nowadays, steel girders with corrugated web plates are used extensively in bridges and large span structures. In this paper, the shear capacity of tapered bridge girders with trapezoidally corrugated webs (BGCWs) has been studied through nonlinear finite element analyses (FEA). The tapered BGCW selected as the subject of this study is a continuous linearly tapered bridge composing from two spans, with emphasis on Cases I and II (see Figs. 3 and 4). In the FEA by using ABAQUS [16], large deflections and material nonlinearity have been taken into account with initial imperfections of $h_{w 1} / 200$. It was found that the web thickness, similar to that in girders with flat webs, has a significant effect on the shear capacity of the specimen. Girders with thicker webs have higher buckling loads. The shear failure was found to take place suddenly. The out-of-plane deformation of the corrugated webs was found to be relatively limited as a result of their significant out-of-plane stiffness, so the failure mode of the BGCWs does not show the propagation of shear plastic hinges at their top flanges similar to those appear in plate girders with flat web plates. It was additionally found that increasing the inclined flange angle significantly reduces the ultimate shear strength of the tapered BGCWs, while the initial stiffness remains more or less the same. The results in general were found to accord with available design strength. 
To check the available design strength for the use with different corrugation dimensions used in conventional structures, different corrugations were considered through varying the angle between the longitudinal and inclined sub-panels $(\alpha)$. Generally, it was noticed that as the value of $\alpha$ decreases, the ultimate shear decreases due to the fact that the web owns less rigidity. It is worth pointing that the web with lower angle among panels has the behaviour similar to flat web panels. Accordingly, a minimum value of $30^{\circ}$ is recommended for the tapered BGCWs.

\section{REFERENCES}

[1] Yi, J., Gil, H., Youm, K. and Lee, H., "Interactive Shear Buckling Behavior of Trapezoidally Corrugated steel webs", Engineering structures, Vol. 30, pp. 1659-1666, 2008.

[2] Moon, J., Yi, J., Choi, B.H. and Lee, H., "Shear Strength and Design of Trapezoidally Corrugated Steel Webs", Journal of Constructional Steel Research, Vol. 65, pp. 1198$1205,2009$.

[3] Eldib, M.E.A., "Shear Buckling Strength and Design of Curved Corrugated Steel Webs for Bridges", Journal of Constructional Steel Research, Vol. 65, pp. 2129-2139, 2009.

[4] Hassanein, M.F. and Kharoob O.F., "Behavior of Bridge Girders with Corrugated Webs: (I) Real Boundary Conditions at the Juncture of the Web and Flanges", Engineering Structures, Vol. 57, pp. 554-564, 2013.

[5] Hassanein, M.F. and Kharoob O.F., "Behavior of Bridge Girders with Corrugated Webs: (II) Shear Strength and Design”, Engineering Structures, Vol. 57, pp. 544-553, 2013.

[6] Hamilton, RW., "Behavior of Welded Girder with Corrugated Webs", Ph.D. thesis, University of Maine, 1993. 
[7] Driver, RG., Abbas HH., Sause R., "Shear Behavior of Corrugated Web Bridge Girders", Journal of Structural Engineering, ASCE, Vol. 132(2), pp. 195-203, 2006.

[8] Nie, J-G., Zhu, Li, Tao, M-X., Tang, L., "Shear Strength of Trapezoidal Corrugated Steel Webs", Journal of Constructional Steel Research, Vol. 85, pp. 105-115, 2013.

[9] Hamada, M., Nakayama,K., Kakihara, M., Saloh, K., Ohtake, F., "Development of welded I-beam with corrugated web," The Sumitomo Search, No. 29, pp. 75-90, 1984.

[10] Chan, C.L., Khalid, Y.A., Sahari, B.B., Hamouda, A.M.S., "Finite Element Analysis of Corrugated Web Beams under Bending", Journal of Constructional Steel Research, Vol. 58(1), pp. 1391-1406, 2002.

[11] Lindner, J., Aschinger, R., "Grenzschubtragfähigkeit Von I-trägern mit Trapezförmig Profilierten Stegen", Stahlbau, Vol. 57(12), pp. 377-380, 1988.

[12] Johnson, R.P. and Cafolla, J., "Corrugated webs in plate girders for bridges", Proceedings of the Institution of Civil Engineers - Structures and Buildings, Vol. 123, pp.157-164, 1997.

[13] Bedynek, A., Real, E., Mirambell, E., "Tapered Plate Girders under Shear: Tests and Numerical research", Engineering Structures, Vol. 46, pp. 350-358, 2013.

[14] Hassanein, M.F. and Kharoob O.F., "Shear Buckling Behavior of Tapered Bridge Girders with Steel Corrugated Webs", Engineering Structures, Vol. 74, pp. 157-169, 2014.

[15] Zevallos, E. J., "Shear Resistance of different web panels of linearly tapered bridge girders with steel corrugated webs", Master Thesis, Department of Construction Engineering, Universitat Politècnica de Catalunya, UPC, Barcelona, Spain, 2015

[16] ABAQUS Standard User's Manual The Abaqus Software is a product of Dassault Systèmes Simulia Corp., Providence, RI, USA Dassault Systèmes, Version 6.8, USA, 2008. 
[17] EN 1993-1-5. Eurocode 3: Design of steel structures - Part 1-5: Plated structural elements. CEN; 2007.

[18] Elgaaly M, Hamilton RW, Seshadri A., "Shear Strength of Beams with Corrugated Webs", Journal of Structural Engineering, ASCE, Vol. 122(4), pp. 390-398, 1996.

[19] Sause, R., Abbas, HH, Wassef, W., Driver, RG, Elgaaly, M., "Corrugated Web Girder Shape and Strength Criteria: Work Area 1", Pennsylvania innovative high performance steel bridge demonstration project. ATLSS report no. 03-18. Bethlehem (PA): Advanced Technology for Large Structural Systems, ATLSS. Center, Lehigh University, 2003.

[20] Ikeda, S., Sakurada, M. "Development of Hybrid Prestressed Concrete Bridges with Corrugated Steel Web Plates", 30th Conference on Our World in Concrete \& Structures, Singapore, 23 - 24 August, 2005, Online version: http://cipremier.com/100030003.

[21] EN 1993-1-1. Eurocode 3: Design of steel structures - Part 1-1: General rules and rules for buildings. CEN, 2004.

[22] He, J., Liu, Y., Lin, Z., Chen, A., Yoda, T., "Shear Behavior of Partially Encased Composite I-girder with Corrugated Steel Web: Numerical study", Journal of Constructional Steel Research, Vol. 79, pp. 166-182, 2012.

[23] Basler, K., Thurlimann, B., "Strength of Plate Girders in Bending", Journal of Structural Division, ASCE, Paper No. 2913, Aug., 1961.

[24] Porter, DM., Rockey, KC., and Evans, HR. "The Collapse Behavior of Plate Girders Loaded in Shear", Struct. Eng., Vol. 53(8), pp. 313-325, 1975.

[25] Lee, SC., Davidson, JS. And Yoo, CH., "Shear Buckling Coefficients of Plate Girder Web Panels", Computers and Structures, Vol. 59, pp. 789-795, 1996.

[26] Wang, X., "Behavior of Steel Members with Trapezoidally Corrugated Webs and Tubular Flanges under Static Loading", Phd thesis, Drexel University, 2003. 
[27] Luo, R., Edlund, B., "Shear Capacity of Plate Girders with Trapezoidally Corrugated Webs", Thin-Walled Structures, V. 26, pp.19-44, 1996.

[28] Kim, K. S., Lee, D. H., Choi, S. M., Choi, Y. H., Jung, S. H., "Flexural behavior of prestressed composite beams with corrugated web: part I. Development and analysis", Composites: Part B, Vol. 42(6), pp. 1603-1616, 2011.

[29] Marques, L., Simões da Silva, L., Rebelo, C., Santiago, A., "Extension of EC3-1-1 Interaction Formulae for the Stability Verification of Tapered Beam-Columns", Journal of Constructional Steel Research, Vol. 100, pp. 122-135, 2014.

[30] Lindner, J., Huang, B., "Beulwerte für trapezförmig profilierte Bleche unter Schubbeanspruchung", Stahlbau, Vol. 64(12), pp. 370-374, 1995. 